\title{
The unique geomorphology and structural geology of the Haulani crater of dwarf planet Ceres as revealed by geological mapping of equatorial quadrangle Ac-6 Haulani
}

\author{
K. Krohn ${ }^{a, *}$, R. Jaumann ${ }^{\text {a,b }}$, K.A. Otto ${ }^{a}$, F. Schulzeck ${ }^{a}$, A. Neesemann ${ }^{b}$, A. Nass ${ }^{a}$, K. Stephan ${ }^{a}$, \\ F. Tosi ${ }^{c}$, R.J. Wagner ${ }^{\mathrm{a}}$, F. Zambon ${ }^{\mathrm{c}}$, I. von der Gathen ${ }^{\mathrm{a}}$, D.A. Williams ${ }^{\mathrm{d}}$, D.L. Buczkowski ${ }^{\mathrm{e}}$, \\ M.C. De Sanctis ${ }^{c}$, E. Kersten ${ }^{a}$, K.-D. Matz ${ }^{a}$, S.C. Mest ${ }^{f}$, C.M. Pieters ${ }^{g}$, F. Preusker ${ }^{\mathrm{a}}$, \\ T. Roatsch ${ }^{\text {a }}$, J.E.C. Scully ${ }^{\mathrm{h}}$, C.T. Russell ${ }^{\mathrm{i}}$, C.A. Raymond ${ }^{\mathrm{h}}$
}

a Institute of Planetary Research, German Aerospace Center (DLR), Berlin, Germany

${ }^{\mathrm{b}}$ Freie Universität Berlin, Inst. of Geosciences, Planetology and Remote Sensing, Berlin, Germany

${ }^{c}$ INAF-IAPS, National Institute for Astrophysics, Rome, Italy

d School of Earth \& Space Exploration, Arizona State University, Tempe, AZ, USA

e JHU-APL, Laurel, MD, USA

f Planetary Science Institute, Tucson, AZ, USA

${ }^{\mathrm{g}}$ Brown University, Providence, RI, USA

${ }^{\mathrm{h}}$ NASA JPL, California Institute of Technology, Pasadena, CA, USA

i UCLA, Los Angeles, CA, USA

\section{A R T I C L E I N F O}

\section{Article history:}

Received 8 August 2016

Revised 21 August 2017

Accepted 1 September 2017

Available online xxx

\begin{abstract}
A B S T R A C T
The dwarf planet Ceres has been explored by NASA's Dawn spacecraft with the goal of characterizing its geology, mineralogy, topography, shape, and internal structure. One outcome of this exploration is the production of geologic maps, meant to unveil the geologic history of Ceres. In this paper, we present the geologic map of the Ac- 6 Haulani quadrangle (Lat. $22^{\circ} \mathrm{S}-22^{\circ} \mathrm{N}$, Long. $0^{\circ}-72^{\circ} \mathrm{E}$ ) based on Low Altitude Mapping Orbit (LAMO) ( $\sim 35 \mathrm{~m} /$ pixel) data supplemented with color and spectral data, as well as a digital terrain model from the High Altitude Mapping Orbit (HAMO) ( $135 \mathrm{~m} /$ pixel, vertical accuracy of about $10 \mathrm{~m}$ ). The $34 \mathrm{~km}$ diameter Haulani crater is one of the youngest features on Ceres and the most prominent one in the quadrangle. Haulani was formed on a topographical transition in north-south direction and shows a complex morphology with a variety of lobate flows and tectonic features. Multiple cracks and depressions around the crater indicate the failure of subsurface material. These were likely formed by the subsidence of material due to the instability of the subsurface. The mapping of Ac-6 Haulani suggests that Ceres is built up of layers with different material properties. We propose that Ceres has a solid crust and a variable ice-rich subsurface consistent with previous and recent models of Ceres' interior.
\end{abstract}

(C) 2017 Elsevier Inc. All rights reserved.

\section{Introduction and geological setting of Ac-6 Haulani}

In 2007 NASA's Dawn spacecraft was launched to study the large asteroid 4 Vesta and the dwarf planet Ceres. After studying 4 Vesta (between July 2011 and September 2012), the Dawn spacecraft then traveled to Ceres and entered into orbit on March 6 th, 2015. It then spent more than one year investigating the geology, elemental and mineralogical composition, topography, shape, and internal structure of the dwarf planet Ceres. As was previously done for 4 Vesta (Williams et al., 2014), the Dawn team con-

\footnotetext{
* Corresponding author.

E-mail address: katrin.krohn@dlr.de (K. Krohn).
}

ducted a systematic geologic mapping campaign at Ceres to understand the geologic history of Ceres. We utilize a successive mapping process, using data obtained during each orbital phase. The mapping campaign includes a 1:10 M global map of Ceres based on Survey data (Buczkowski et al., 2016), a global map, at a scale of 1:1000,000, generated with HAMO images ( $140 \mathrm{~m} /$ pixel) (Mest et al., 2017; Williams et al., 2017a, this issue) and a set of 15 quadrangle maps (Fig. 1), at a scale of 1:500,000, generated with LAMO images ( $\sim 35 \mathrm{~m} /$ pixel), (Roatsch et al., 2016b; Williams et al., 2017a, this issue). Further details about the geologic mapping campaign are included in the introductory paper to this special issue (Williams et al., 2017a). 

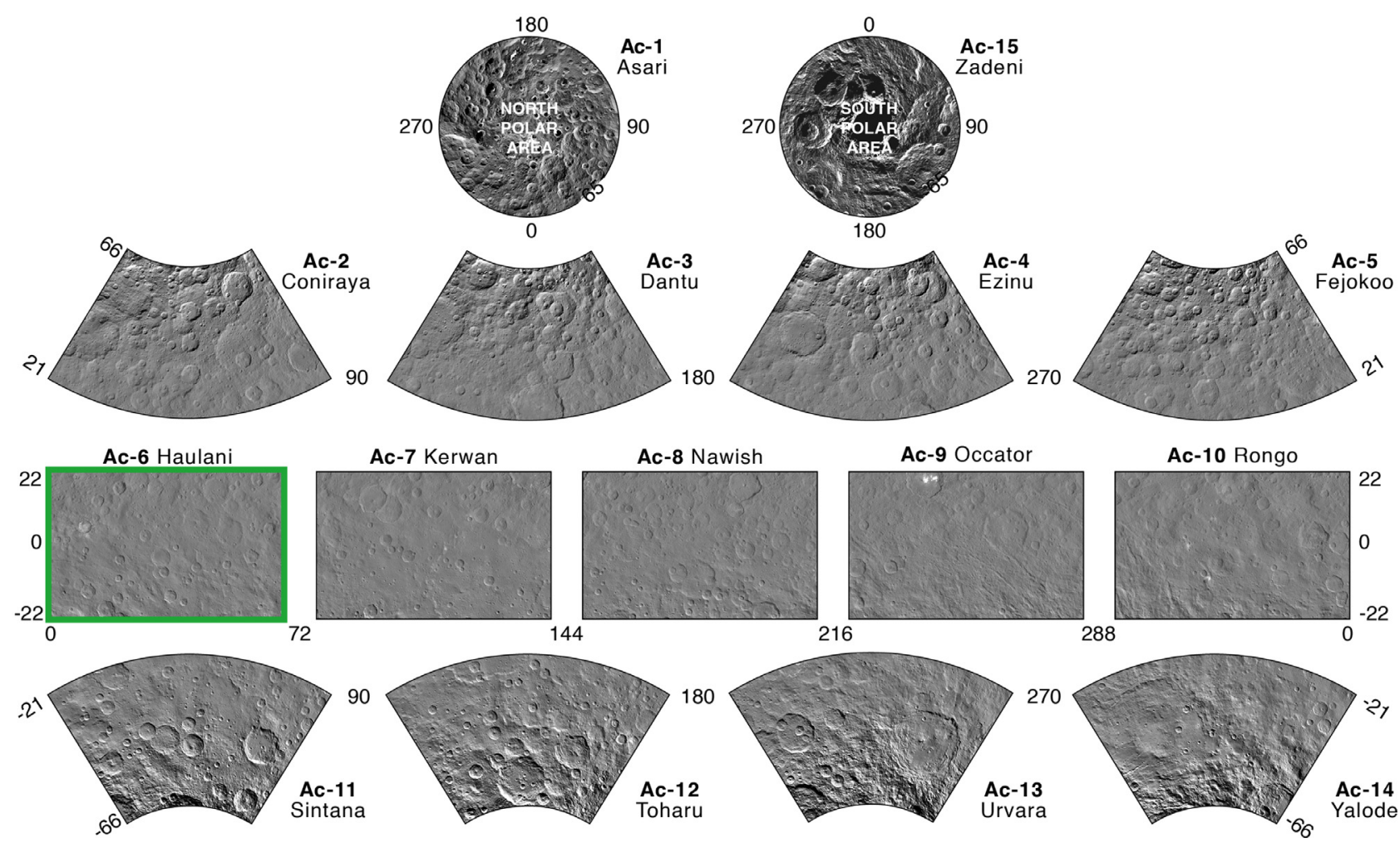

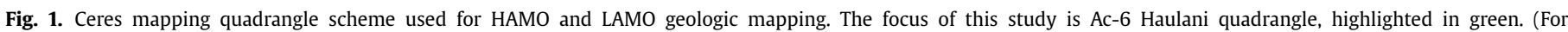
interpretation of the references to color in this figure legend, the reader is referred to the web version of this article.)

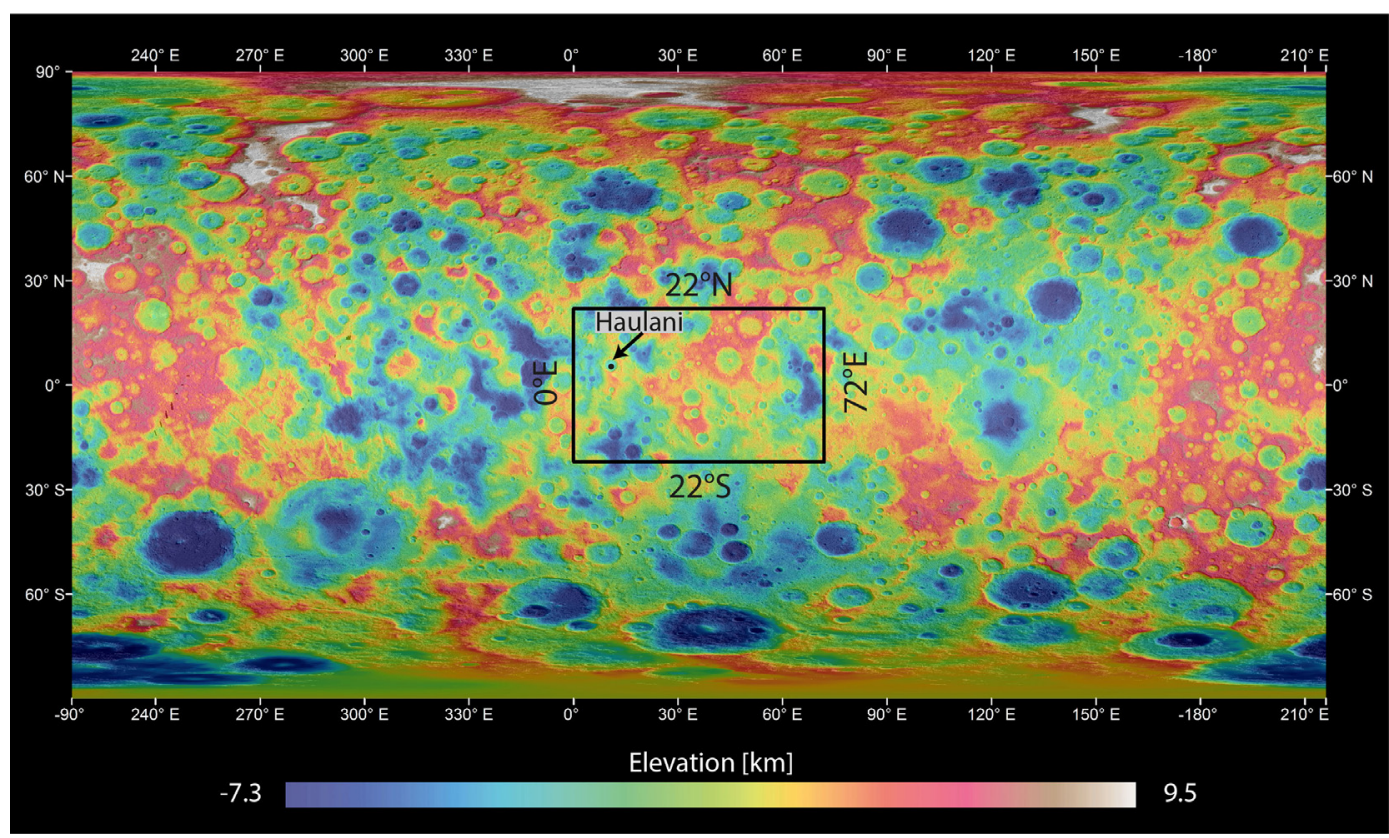

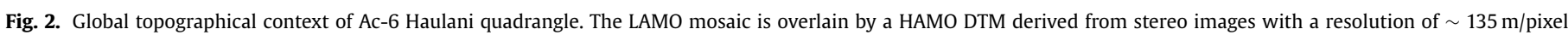
(vertical accuracy of about $10 \mathrm{~m}$ ) (Preusker et al., 2016), and is in an equidistant cylindrical projection using the Kait coordinate system (Roatsch et al., 2016a).

In this paper we mapped the surface of the equatorial quadrangle Ac- 6 Haulani. Ac- 6 is located around the equator between $22^{\circ} \mathrm{S}-22^{\circ} \mathrm{N}$ and $0^{\circ}-72^{\circ} \mathrm{E}$ (Fig. 2). This quadrangle is named after the Haulani crater, which is one of the brightest features on Ceres and approximately $34 \mathrm{~km}$ in diameter. The topography of Ac- 6 is characterized by a high plateau in the center of the quadrangle, extending northward into the Ac-2 Coniraya quadrangle (Pasckert et al., 2017, this issue) and eastward into the Ac-7 Kerwan quadrangle
(Williams et al., 2017b, this issue) (Fig. 1). Some deeper depressions are located in the northwest, east, and southwest. The overall elevation differs from approximately $-5.6 \mathrm{~km}$ to approximately $3.8 \mathrm{~km}$ above the reference ellipsoid (radii: $482 \mathrm{~km} \times 482 \mathrm{~km} \times$ $446 \mathrm{~km})$.

Ac-6 is mainly composed of a cratered material unit, but the most interesting and dominating feature of the quadrangle is the Haulani crater itself. Haulani is one of the freshest and youngest 


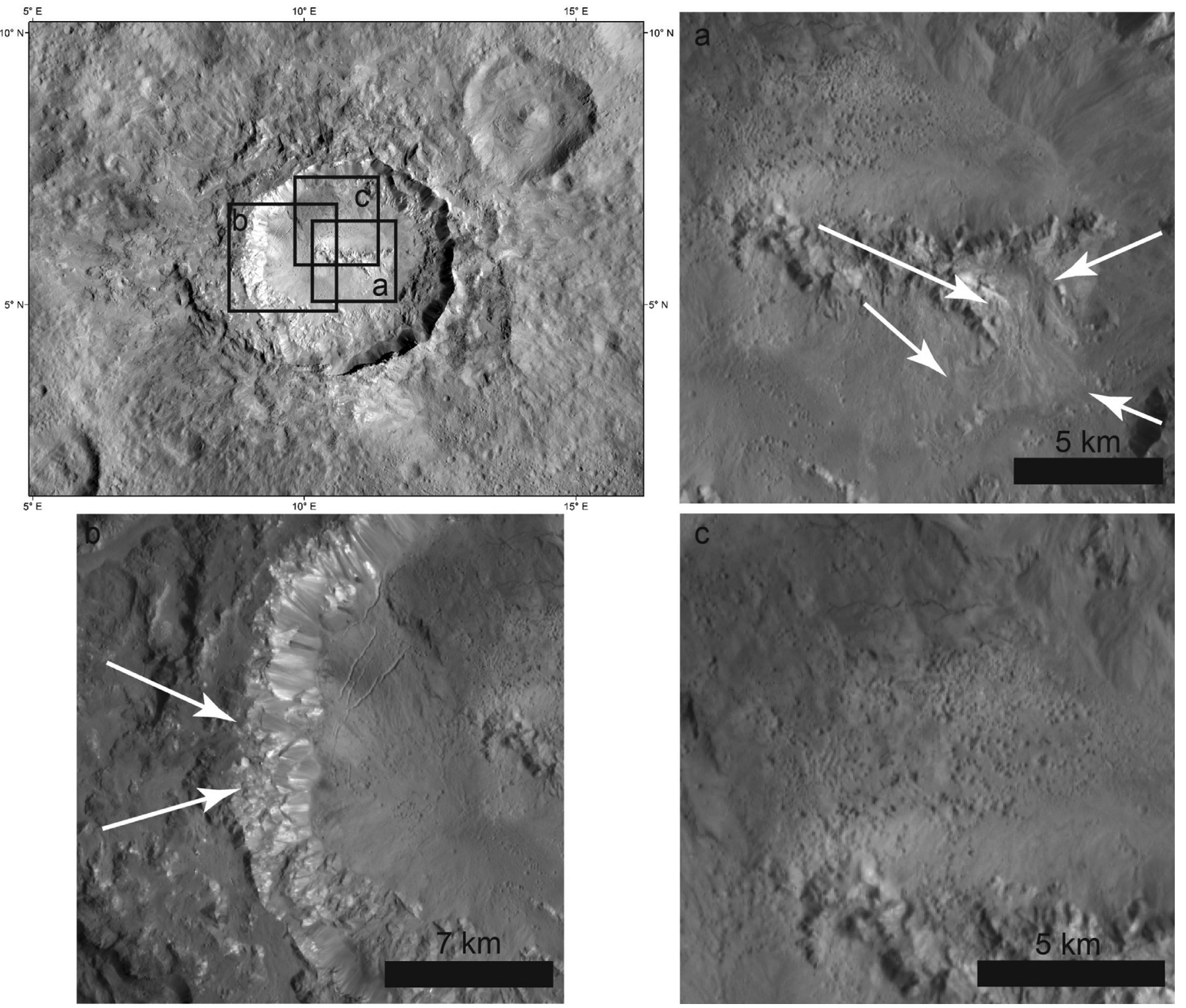

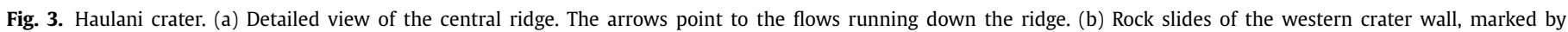
arrows. (c) Detailed view of the pitted terrain on Haulani's crater floor.

craters on Ceres. Its bright ejecta is widespread over the cerean surface, preferentially to the west (Fig. 5), extending into quadrangle Ac-10 Rongo (Platz et al., 2017, this issue). Haulani (Fig. 3) was formed on the transition between a central plateau in the east and a topographic low in the west (Fig. 7). The crater shows a sharp rim in the north, east, and south (Fig. 3). The southern and especially the southeastern outer crater rim reveal a steep slope resulting in a depression within the crater flank, indicating the failure of material. The western part is characterized by a collapsed crater rim, steep scarps, and several fractures, also implying the failure of material (Fig. 3). Furthermore, Haulani is affected by several different flow types, predominantly covering the western crater flank (Krohn et al., 2016a, 2016b).

Adjacent to the west of Haulani are two small tholi, meaning domical mountains or hills (singular, tholus): the well-defined elongated Dalien Tholus (length: $\sim 22 \mathrm{~km}$, width: $\sim 14 \mathrm{~km}$ ) and an unnamed one (length: $\sim 28 \mathrm{~km}$, width: $\sim 16 \mathrm{~km}$ ) with an irregular shape (Fig. 7). Both tholi have a maximum height of $1.45 \mathrm{~km}$. The bulge of the adjacent impact crater and since the tholus is not cut by the impact indicates that Dalien Tholus was formed after the impact. Another tholus, named Wangala Tholus, is located in the southwest and is transected almost equally by the boundary between Haulani and Sintana quadrangle (Schulzeck et al., 2016, this issue) (Fig. 7). Wangala Tholus is about $70 \mathrm{~km}$ in length, $54 \mathrm{~km}$ in width, and $1.6 \mathrm{~km}$ high with moderate flanks. The part of the tholus in the Haulani quadrangle is relatively circular, while the southern part in the Sintana quadrangle shows an irregular basal shape (see Schulzeck et al., 2016, this issue). The quadrangle also shows swirled crater floors, pit chains, grooves, channels, troughs, ridges, and a set of furrows. Linear depressions cross the quadrangle in a west-east direction, with a slight tendency to the northwest. Geologic units of this region include: pitted terrain, talus material, smooth material, several lobate materials and different crater materials.

In this paper, we discuss the geologic and tectonic histories of the Haulani crater. 


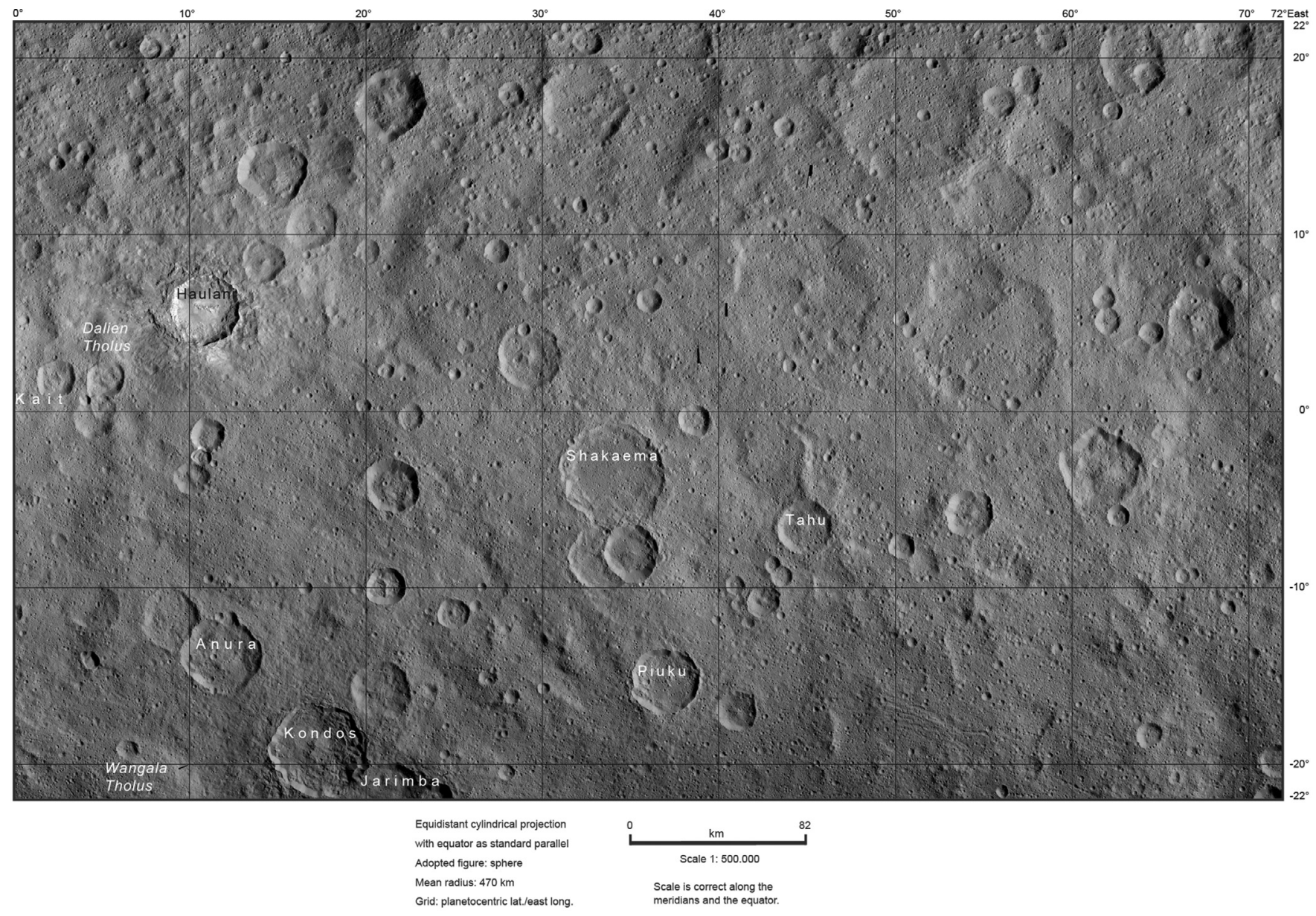

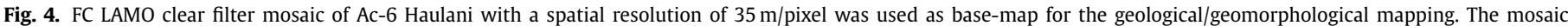
is in an equidistant cylindrical projection using the Kait coordinate system (Roatsch et al., 2016a). The mosaic was provided by the German Aerospace Center (DLR).

\section{Datasets and methods}

For mapping the quadrangle and the analysis of Haulani crater, Dawn Framing Camera (FC) data (Sierks et al., 2011) and Visible and Infrared Spectrometer (VIR) (De Sanctis et al., 2011) data, as well as the digital terrain model (DTM) developed by Preusker et al. (2016), were used. The data processing of the FC images is described in Roatsch et al. (2016a). During the orbital phases, the FC and the VIR mapped the surface with image scales of $\sim 410 \mathrm{~m} /$ pixel (FC) and $\sim 1000 \mathrm{~m} /$ pixel (VIR) in the Survey phase, $\sim 140 \mathrm{~m} /$ pixel (FC) and $\sim 420 \mathrm{~m} /$ pixel (VIR) in the High Altitude Mapping Orbit (HAMO), and $\sim 35 \mathrm{~m} /$ pixel (FC) in the Low Altitude Mapping Orbit (LAMO).

As basemap for the geologic mapping, we primary used a mosaic of high-resolution LAMO clear filter images, provided by the German Aerospace Center (DLR) (Fig. 4). To support the mapping, we also used single LAMO FC images to refine the mapping with different solar illuminations and greyscale stretches for regions of special interest. Furthermore, we used an enhanced ('false') FC HAMO color ratio mosaic of the filters $5(956 \mathrm{~nm}), 2$ $(555 \mathrm{~nm})$, and $8(440 \mathrm{~nm})$ (Fig. 5) and a HAMO color composite 'R' mosaic $(R=965 / 750 \mathrm{~nm} ; G=550 / 750 \mathrm{~nm} ; B=440 / 750 \mathrm{~nm})$ (Fig. 6) (Pieters et al., 2016), also provided by the DLR. Both mosaics have a lower resolution compared to the clear filter mosaic, and were used to refine and identify the boundaries of the geological units, as well as to distinguish between mineralogical differences and to recognize features which cannot be identified in the FC clear filter images. The red channel displays variations in the longer wavelengths, the green variations in the peak wavelength, and the blue variations in the shorter wavelengths. Topographic data of Ceres (Fig. 7) derived from the Dawn HAMO FC stereo images with a resolution of $\sim 135 \mathrm{~m} /$ pixel (vertical accuracy of about $10 \mathrm{~m}$ ) (Preusker et al., 2016) also helped to map and define stratigraphic units and structure.

The maps presented here use an IAU-approved coordinate system, which was anchored by the $0.4 \mathrm{~km}$-diameter reference crater Kait at $2.1^{\circ} \mathrm{S}, 0^{\circ} \mathrm{E}$ (Roatsch et al., 2016a).

Geological mapping of the surface units was performed following the guidelines of Wilhelms (1990), Hansen (2000) and Skinner et al. (2003). For the mapping we used ESRI's software package ArcGIS 10.4. The cartographic visualization of identified objects based on the Digital Cartographic Standard for Geologic Map Symbolization defined by the Federal Geographic Data Committee (FGDC, 2006). The mapping investigation was supported by a predefined GIS-based implementation of cartographic symbology (including geological map units) and data structure (including object description) by Nass et al. (2011) and Nass et al. (2015).

For the age determinations, we used the two cerean chronology systems developed by the Dawn Science Team (Hiesinger et al., 2016): the asteroid flux-derived chronology and the lunar-derived model. The production function of the asteroid flux-derived model based on the directly observed object size-frequency distribution from the main asteroid belt (extended to sizes $<5 \mathrm{~km}$ by a collisional model) to the resulting size-frequency distribution of cerean craters (Hiesinger et al., 2016). However, the lunarderived chronology system is based on the lunar cratering chronol- 


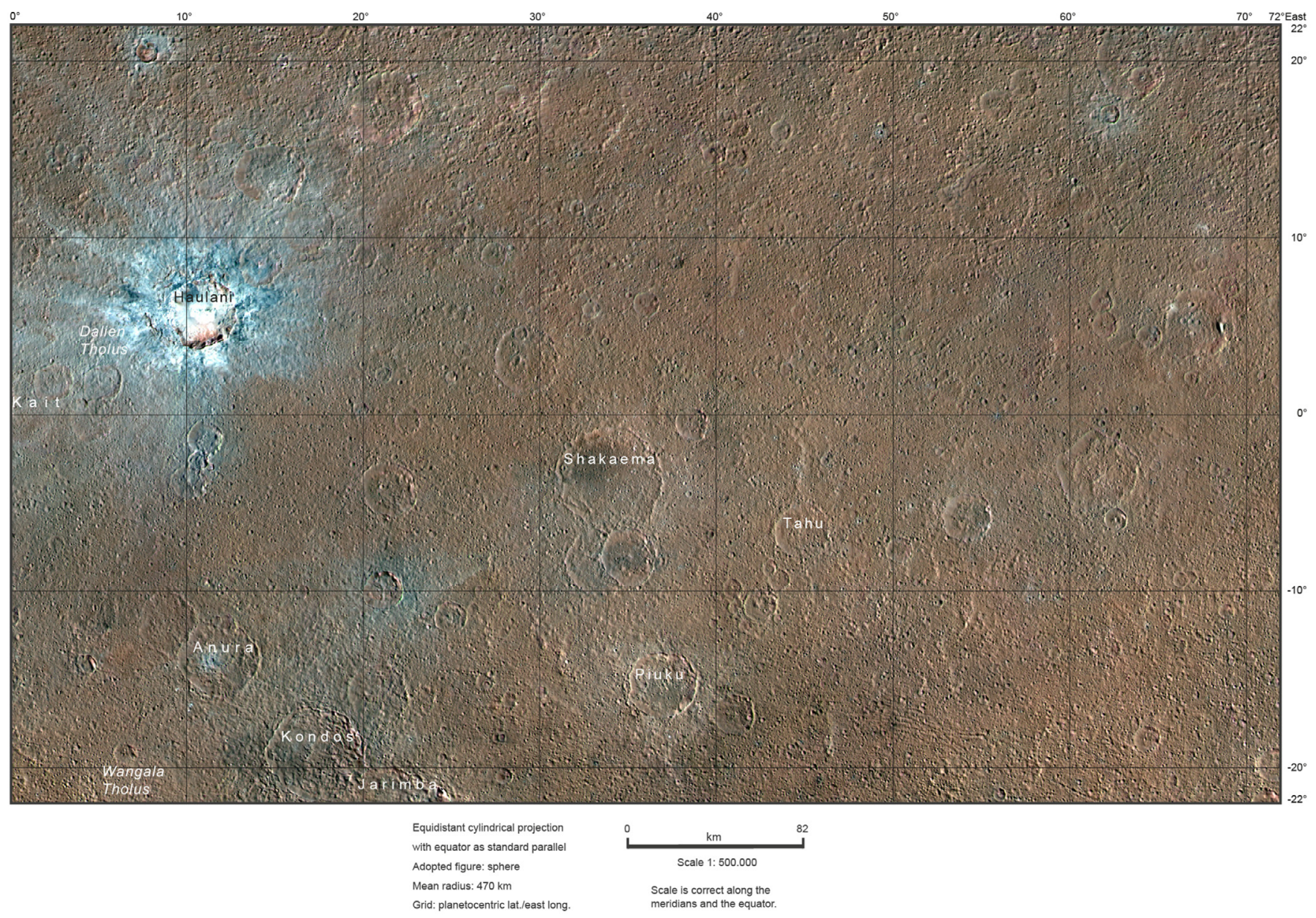

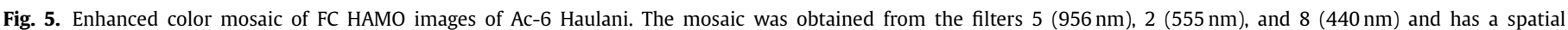

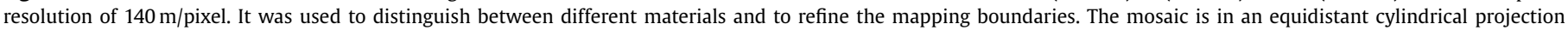
using the Kait coordinate system (Roatsch et al., 2016a) and was provided by the German Aerospace Center (DLR).

ogy and was adapted to impact conditions on Ceres, considering impact velocities, projectile densities, current collision probabilities, and surface gravity (Hiesinger et al., 2016). Both chronologies were developed, using similar cerean target parameters. The differences of both chronology systems are discussed in detail in Hiesinger et al. (2016).

For the representation of the ages, we used a Poisson timing analysis technique from Michael et al. (2016). This new technique expresses the results as a likelihood function which is the exact prediction of the model. For a detailed understanding of this technique, the reader is directed to Michael et al. (2016).

\section{Geologic setting/mapping results}

We mapped the Ac-6 Haulani quadrangle at a scale of $1: 100,000-1: 125,000$ and presented the geologic map of in Fig. 9 at a scale of $1: 2000,000$. A high resolution image of the $1: 1000,000$ geologic map of Haulani quadrangle is available in the Supplementary Material. A relative correlation of map units is shown in Fig. 10. The following section provides descriptions and interpretations of the units defined in Ac-6, and type examples are given in Fig. 8.

\subsection{Cratered material (unit crt)}

Description: The cratered material (unit crt) is the most extensive unit in the Ac-6 Haulani quadrangle and is characterized by a high crater density. The craters vary from round-shaped to polygonal-shaped (Otto et al., 2016), and their floors are typically shallow and are superposed by ejecta from other impacts. They also show varying degradation states. Some craters show very degraded to non-existent crater rims and are only visible in the DTMs. In the Haulani quadrangle, a lot of younger pit crater chains, grooves, and furrows mark the surface of the cratered material, as well as fresh to degraded crater stages. This unit covers the central plateau, which is connected to a northward extending highland, as well as the depressions. Unit crt displays an intermediate albedo in the FC clear filter images, and a reddish/brownish color in the enhanced FC color images. Type area: lat. $16.9^{\circ} \mathrm{N}$, long. $50.7^{\circ} \mathrm{E}$.

Interpretation: Due to the high crater density, this unit is interpreted as the ancient crust of Ceres, composed of silicates, carbonates, salts, and water ice (De Sanctis et al., 2015; De Sanctis et al., 2016). Unit crt is superposed by all other units and has been degraded by either the emplacement of ejecta blankets, the degradation of sloping material over time, or space weathering.

\subsection{Crater central peak material (unit $c c p$ )}

Description: Crater central peak material occurs as cones, like in the case of Kondos crater, or as mountainous ridges with rugged surfaces, like in the case of Haulani crater. Unit сср is characterized by relatively steep slope angles and a lower crater density. The central ridge of the Haulani crater shows flow features. These flow features, which originate from the central ridge, display chan- 


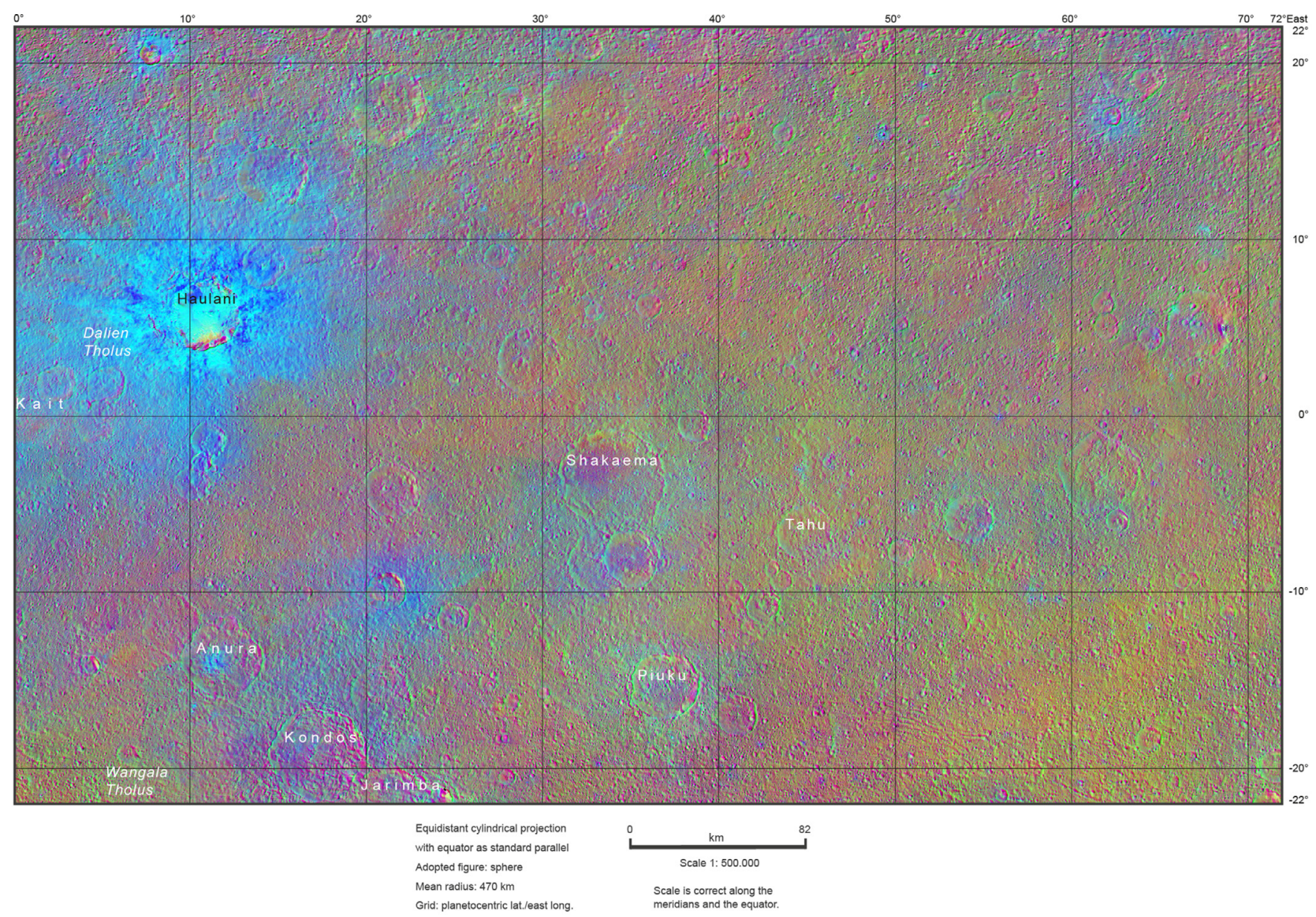

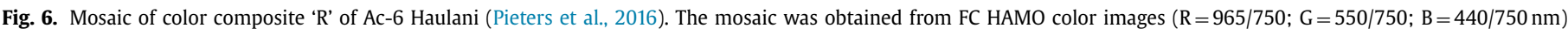

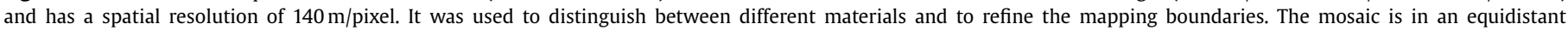
cylindrical projection using the Kait coordinate system (Roatsch et al., 2016a) and was provided by the German Aerospace Center (DLR).

nels, streams, lobes, and well-defined flow fronts (Krohn et al., 2016a,2016b). Type area: lat. $5.8^{\circ} \mathrm{N}$, long. $10^{\circ} \mathrm{E}$.

Interpretation: Central peaks are the result of uplifts of the materials, which originally underlie the central region of the transient cavity (Kuiper, 1954). Thus, subsurface materials are exposed on the surface. Unit ccp of Haulani likely consists of a more fluid-like material. It is possible that the crater central peak material was formed by a more recent outflow.

\subsection{Crater floor materials (units $c f, c f d, c f s, c f s b, c s f d$ )}

Description: Crater floor materials on Ceres' surface can be divided into several subunits. Crater floor material (unit $c f$ ) is a moderate cratered surface which contains only small craters. The albedo of unit cf in FC clear filter images is similar to the surroundings, but shows a reddish color in the enhanced FC color images (Type area: lat. $3.7^{\circ} \mathrm{S}$, long. $35^{\circ} \mathrm{E}$ ). Crater floor material dark (unit $c f d$ ) has a similar morphology and albedo as unit cf, but in the enhanced FC color images, this unit appears dark blue to black. Unit cfd was only identified in the Shakaema crater (Type area: lat. $2.4^{\circ} \mathrm{S}$, long. $33^{\circ} \mathrm{E}$ ). Crater floor material smooth (unit cfs) has a very smooth surface without craters, and only a few pits as well as some cracks and pit crater chains are visible. The albedo in FC clear filter images appears a bit darker than the surroundings, and the enhanced FC color images reveal a bluish to brownish color (Type area: lat. $6.4^{\circ} \mathrm{N}$, long. $9.6^{\circ} \mathrm{E}$ ). The crater floor material smooth dark (unit $c f s d$ ) also shows the same morphological characteristics as unit cfs, but additionally contains a lot of pits and some small, narrow, lobate channels. The channels are irregular distributed and appear as dark depressions. Unit cfsd is deposited on the topographically higher parts of the crater interior. The albedo is significantly darker than the surrounding areas, and the enhanced color mosaic shows a dark blue color (Type area: lat. $6.8^{\circ} \mathrm{N}$, long. $\left.10.2^{\circ} \mathrm{E}\right)$. Compared to the other smooth crater floor material units, the crater floor material smooth bright (unit cfsb) displays similar morphological characteristics, but no linear features are visible, and the albedo is significantly higher than the surroundings. The enhanced color mosaic reveals a light blue to almost white color. Smooth crater floor materials only occur in Haulani crater (Type area: lat. $35.2^{\circ} \mathrm{N}$, long. $10.1^{\circ} \mathrm{E}$ ).

Interpretation: These units were formed due to emplaced material excavated by impact processes. Different spectral behavior is possibly due to different subsurface materials excavated from deeper, inhomogeneously distributed layers. Larger projectiles can hit a deeper layer, than smaller ones. Additionally, the smoother appearance of the units could be also due to different subsurface materials. Fine-grained or saturated material forms most likely a smooth surface. The channels of unit cfs are probably formed due to erosion (mechanical, thermal, thermomechanical) (Boyce et al., 2012; Tornabene et al., 2012). Therefore, the formation of pits indicates a volatile-rich material. A more detailed discussion of the pits is presented in Section 4. 


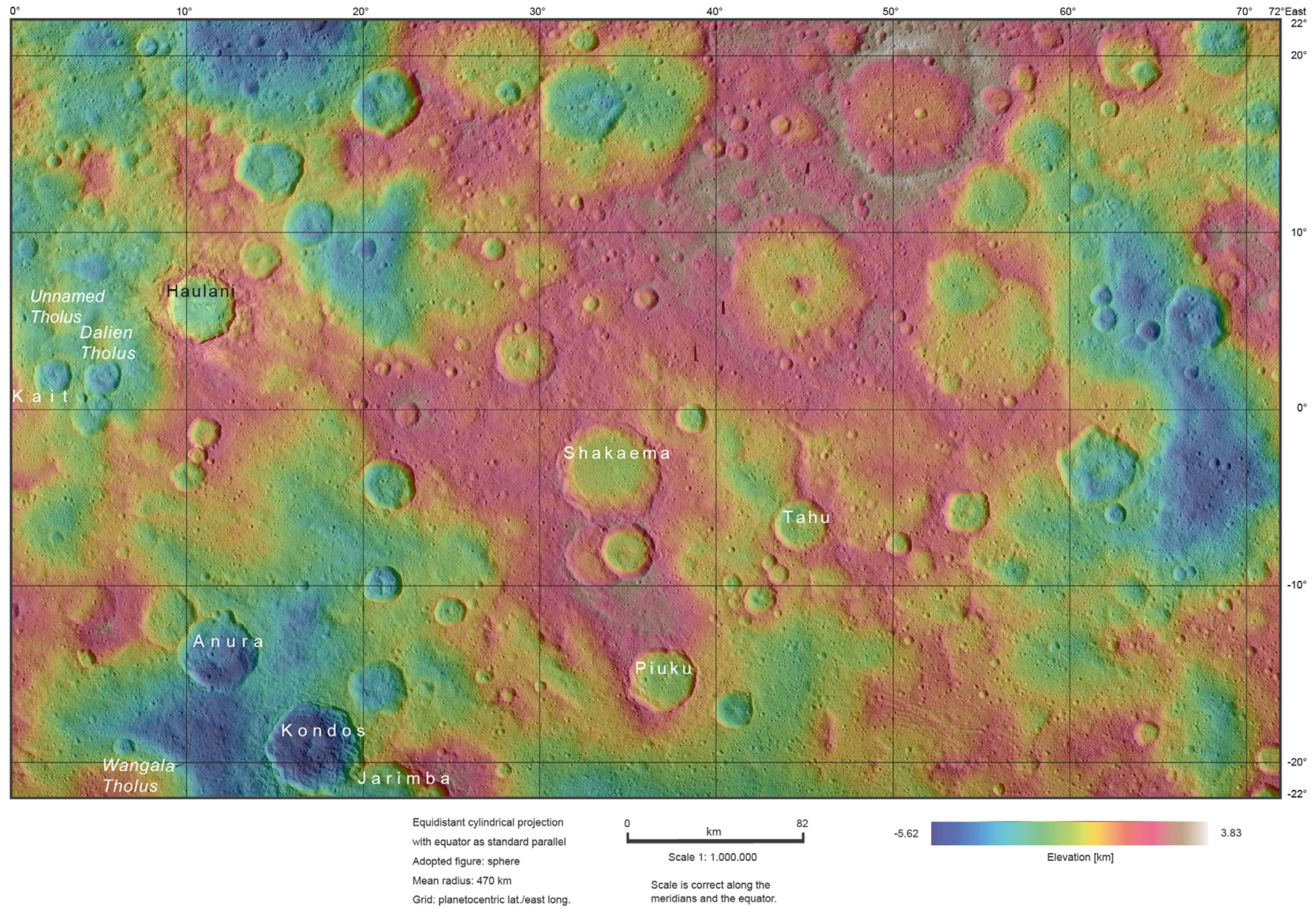

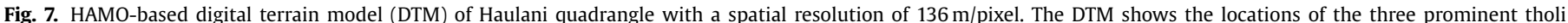

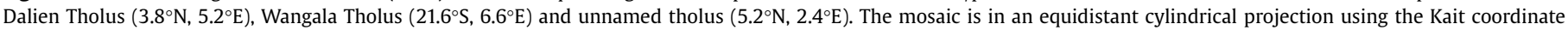
system (Roatsch et al., 2016a).

\subsection{Lobate materials (units $l, l b, l s b$ )}

Description: Various craters have modified floors with undivided lobate material, which can be divided into several subunits. Lobate material (unit l) is characterized as tongue-shaped masses. The unit is mainly localized on crater floors with generally a lower crater density than the surrounding materials. While the FC clear filter images reveal an intermediate albedo, the enhanced FC color mosaic shows a reddish color (Type area: lat. $20.5^{\circ} \mathrm{N}$, long. $7.7^{\circ} \mathrm{E}$ ). Lobate material bright (unit $\mathrm{lb}$ ) reveals a smooth, relatively finegrained surface with multiple flow stages of viscous flows on top of each other on the western crater flank of Haulani (Krohn et al., 2016b). The smooth surface of unit $\mathrm{lb}$ can be also interrupted by some knobs (northern and eastern crater flank of Haulani). Unit $\mathrm{lb}$ exhibits a high albedo compared to the surrounding terrain in the FC clear filter images, while colors vary from white to different shades of blue in the enhanced color mosaic (Type area: lat. $6.3^{\circ} \mathrm{N}$, long. $7.4^{\circ} \mathrm{E}$ ). Lobate material smooth bright (unit lsb) displays a pristine smooth surface with fine-grained material, which forms debris-like deposits with lobate tongues or cone- to fan-shaped morphology, extending from crater rims to crater floors. This unit is located within fresh craters, like Haulani and adjacent craters on Haulani ejecta. The unit exhibits some flow features and a streaklike patterned or swirled, slightly channelized, surface. The albedo of unit lsb is high in the FC clear filter images, while the colors vary from white to different shades of blue in the enhanced color mosaic (Type area: lat. $8^{\circ} \mathrm{N}$, long. $13.9^{\circ} \mathrm{E}$ ).
Interpretation: Most lobate material is possibly related to mass wasting processes due to impact-driven forces. They are likely flow deposits and might be the result of either impact ejecta flow lobes or impact debris which moved downslope as mass wasting material or impact melt. However, the more flow-like lobate material associated with Haulani crater could be the result of the mobilization of liquid material from a subsurface layer, which was discharged through the impact (Krohn et al., 2016b).

\subsection{Pitted material (unit $p$ )}

Description: This unit is composed of pits, variable in size. The pits are nearly circular rimless and located in clusters on the smooth crater floor and ejecta of the Haulani impact structure. The pit diameters range from hundreds of meters down to $\sim 34 \mathrm{~m}$ near the limit of LAMO resolution (Krohn et al., 2016b). The largest pits are found in the ejecta. All pits are formed on the bluish material (Type area: lat. $6.5^{\circ} \mathrm{N}$, long. $10.5^{\circ} \mathrm{E}$ ).

Interpretation: The pits could have formed due to the rapid degassing of liquid material from the subsurface (Boyce et al., 2012; Tornabene et al., 2012). Therefore, the formation of pits indicates a volatile-rich material. A more detailed discussion of the pits is presented in Section 4.

\subsection{Talus material (unit ta)}

Description: Talus material (unit ta) is composed of relatively smooth material and is located at the crater walls below the crater 

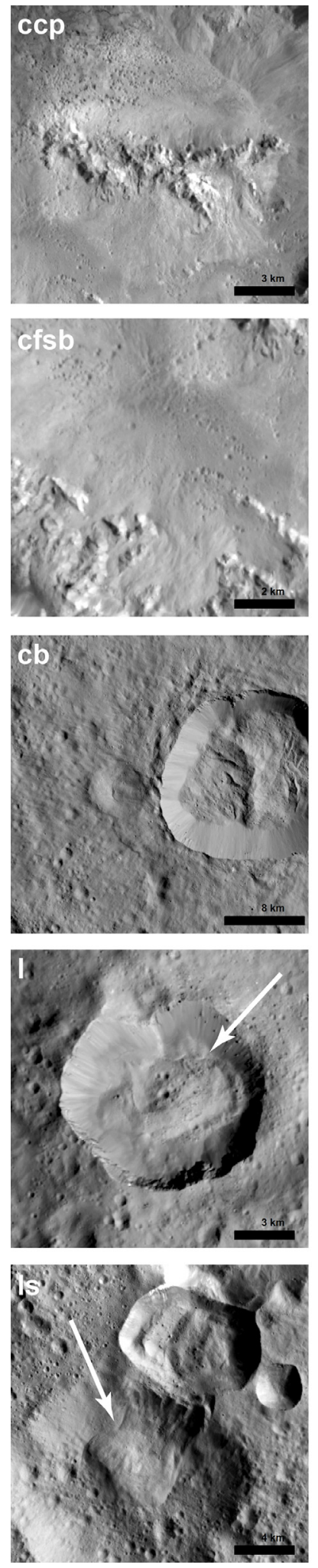
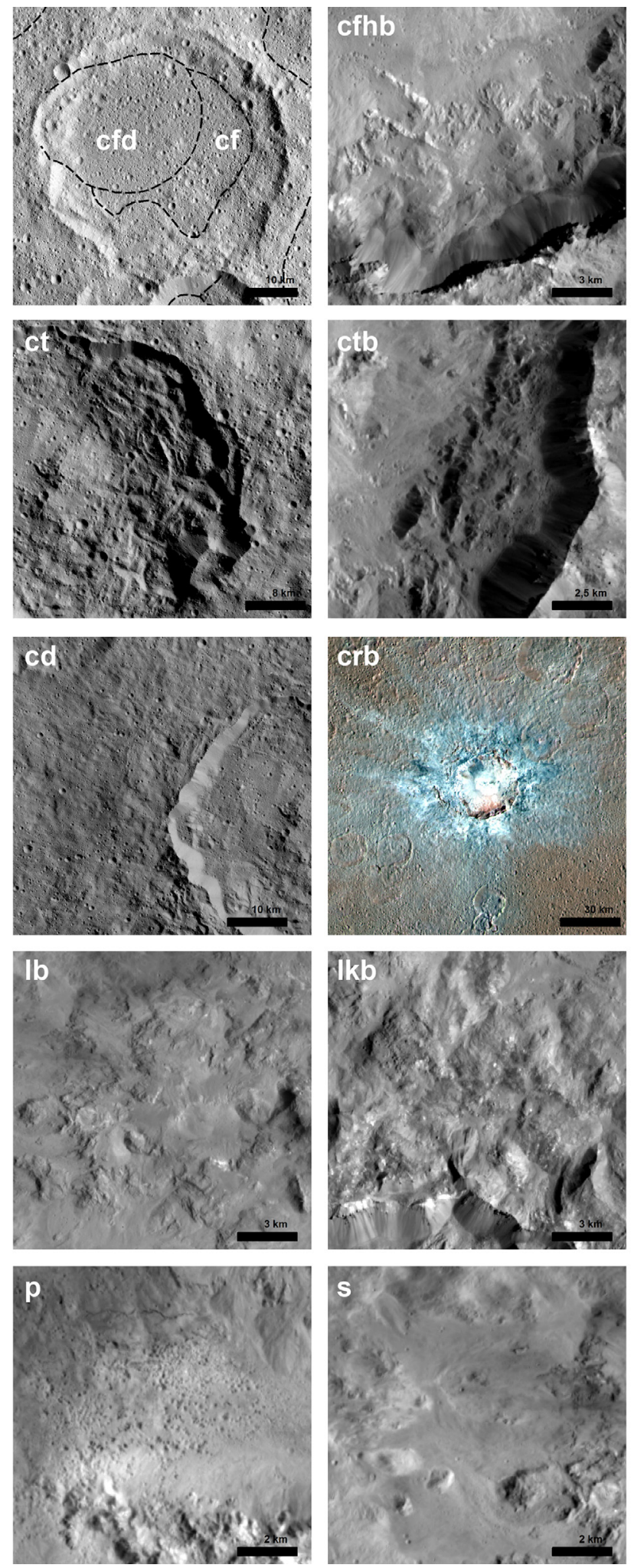
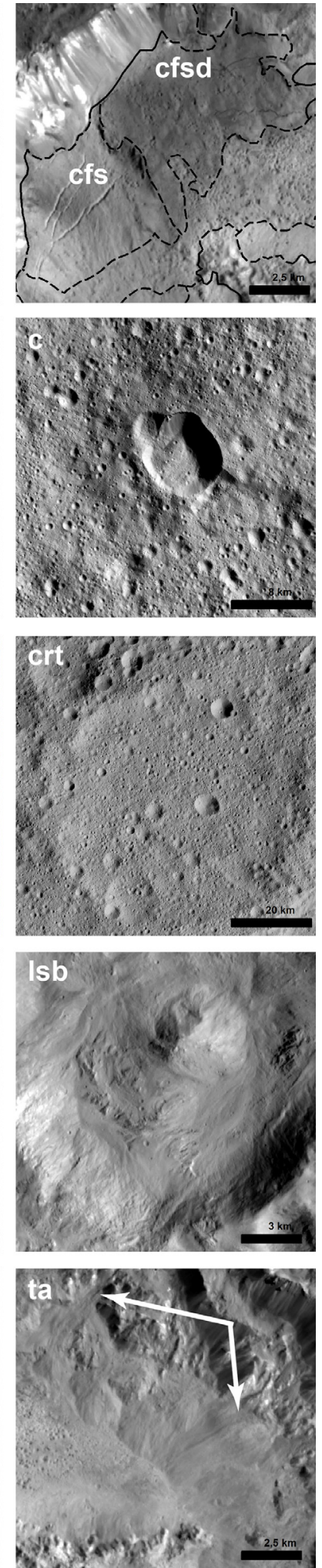

Fig. 8. Type examples of material units of the geologic map of Ac-6 (see Fig. 9). White arrows indicate the type feature of some of the units. Unit crb-enhanced color mosaic of the Haulani impact crater shows the bright crater rays. Latitude-longitude coordinates of these examples are given in the text respectively (Section 3). (For interpretation of the references to color in this figure legend, the reader is referred to the web version of this article.)

rims. Talus material is found on younger, relatively fresh craters, like the Haulani crater and an unnamed one at $8^{\circ} \mathrm{S}, 35^{\circ} \mathrm{E}$. Type area: lat. $6.5^{\circ} \mathrm{N}$, long. $11.4^{\circ} \mathrm{E}$.
Interpretation: This unit likely consists of mass wasting deposits of fine-grained unconsolidated materials formed through slope failure possibly driven by oversteepened slopes and seismic shaking. 


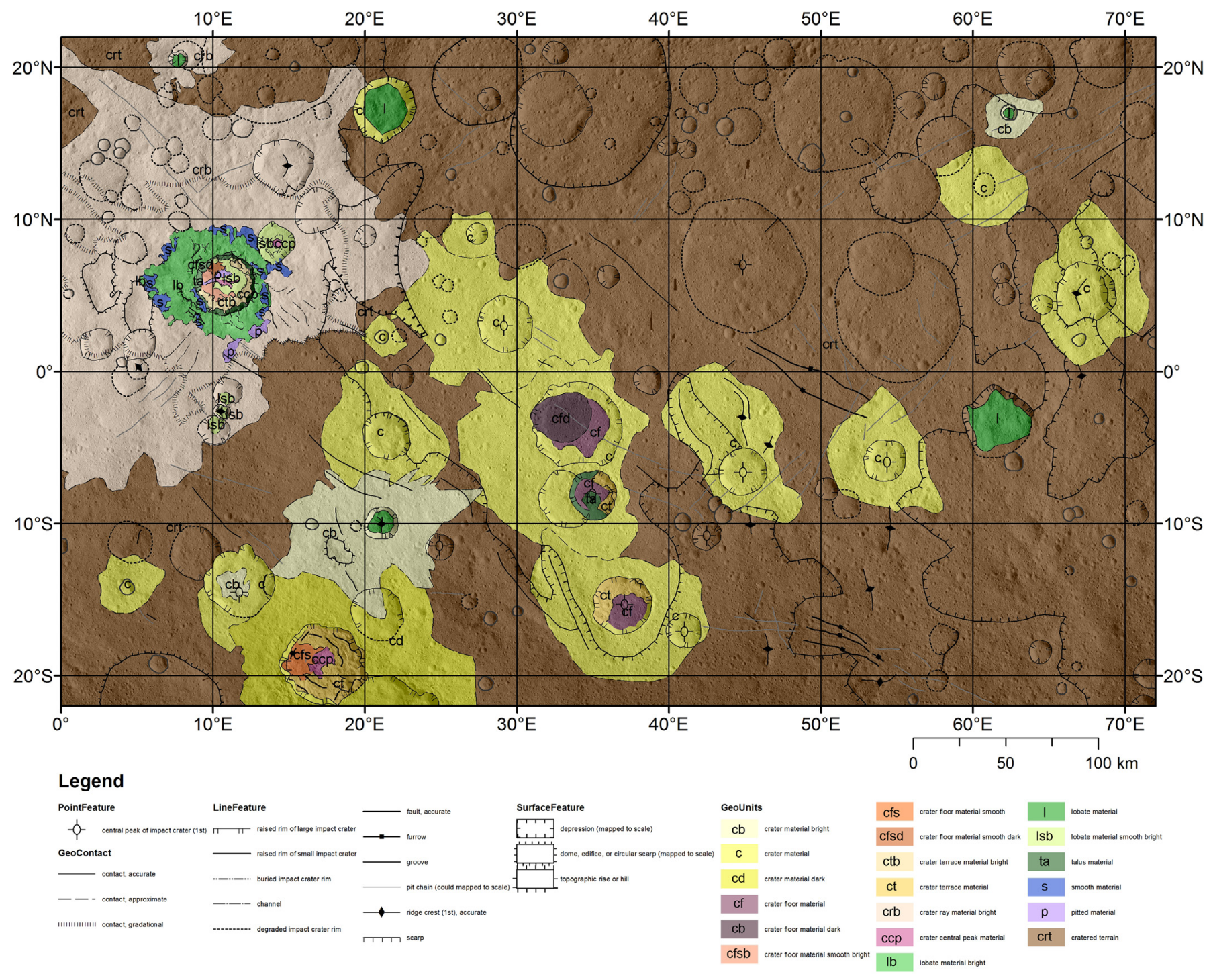

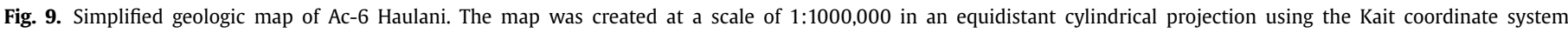

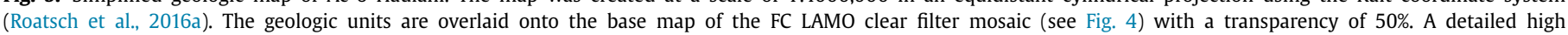
resolution version of this geologic map is provided in the supplementary material (SM).

\subsection{Crater terraced materials (units $c t$ and $c t b$ )}

Description: Crater terraced materials in Ac-06 have a low crater density. They occur as stair-step-like arcuate concentric slump features and exhibit a shallower slope than the scarp wall. They are found along the inner crater wall. Crater terrace material (unit ct) exhibits a similar albedo as the surrounding material in FC clear filter images, but shows a reddish color in the enhanced FC color images (Type area: lat. $18.6^{\circ} \mathrm{S}$, long. $18.3^{\circ} \mathrm{E}$ ). However, crater terrace material bright (unit ctb) reveals a high albedo, and a blue to almost white color in the enhanced color mosaic. Moreover, unit ctb is only identified in Haulani crater, and craters on the surface are not visible (Type area: lat. $5.5^{\circ} \mathrm{N}$, long. $\left.12^{\circ} \mathrm{E}\right)$.

Interpretation: This unit consists of terrace-forming blocks, which are either sections of the transient cavity rim that slumped into the crater during the modification stage of crater formation (Melosh, 1989) or rotational rock slumps associated with slope instability and gravitationally triggered events (such as seismic shaking produced by impacts or internal quakes).

\subsection{Smooth material (unit s)}

Description: This unit is composed of fine-grained material with a smooth featureless surface. This material occurs as well-defined lobes incising the flank of Haulani crater. A few lobes are dissected by channels, and some show streams and flow fronts on the surface (Krohn et al., 2016a, 2016b). This unit exhibits high albedo compared to the surrounding terrains in the FC clear filter images, as well as a bluish pattern in the enhanced color mosaic. Type area: lat. $6.5^{\circ} \mathrm{N}$, long. $10.6^{\circ} \mathrm{E}$.

Interpretation: This unit either consists of impact melt or cryovolcanic material.

\subsection{Crater materials (units $c, c b, c d$ )}

Description: Crater materials are generally much smoother and fresher compared to the surrounding cratered material (crt). These materials are located in- and outside individual well defined craters, and can be separated into three units in Ac-06. Crater material (unit c) is located on crater rims and floors and forms a continuous relatively smooth and less cratered surface. The albedo 


\section{Correlation of Map Units Ac-6 Haulani Quadrangle, Ceres}

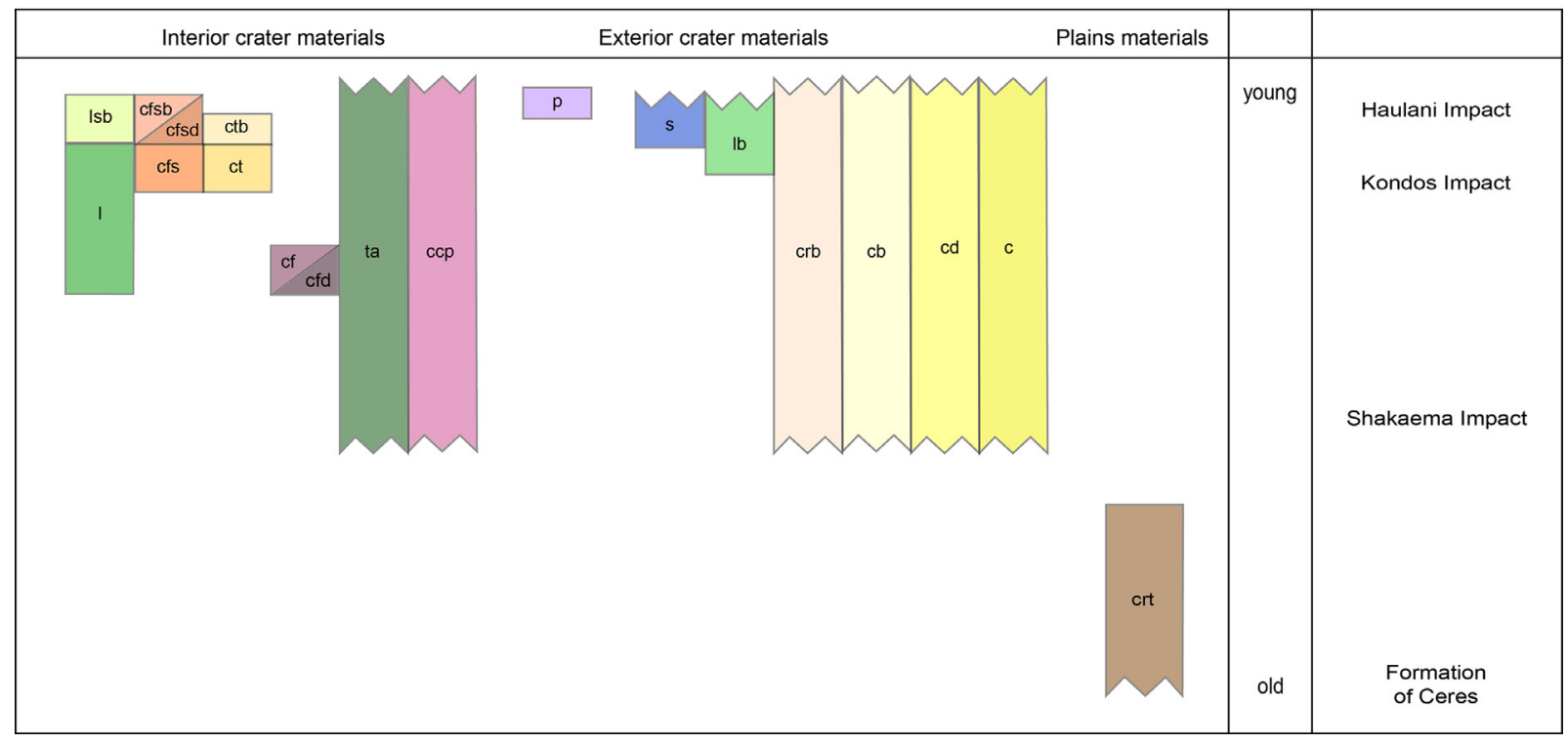

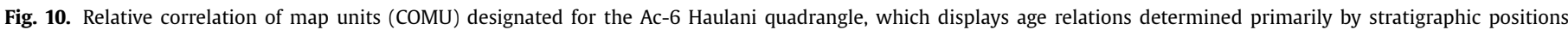
(cross-cutting relations) and crater counts.

of this unit is similar to the surrounding areas and the enhanced color mosaic shows the same reddish color as the surroundings (Type area: lat. $14.2^{\circ} \mathrm{S}$, long. $4.2^{\circ} \mathrm{E}$ ). Bright crater material (unit cb) shows the same morphological and albedo characteristics as unit c, but the unit reveals a blue color in the enhanced color mosaic and in the color ratio composite A (Type area: lat. $9.9^{\circ} \mathrm{S}$, long. $19.9^{\circ} \mathrm{E}$ ). Crater material dark (unit cd) is only found at Kondos crater and covers also crater rim, floor forming a continuous surface. This surface is also affected by radial flow-like features. Unit cd shows a slightly lower albedo than the adjacent areas and appears dark blue to black in the enhanced color mosaic and violet in the color ratio composite A (Type area: lat. $18.5^{\circ} \mathrm{S}$, long. $14^{\circ} \mathrm{E}$ ).

Interpretation: These units consist of relatively fresh and unmodified crater deposits, including rim, ejecta, and floor materials. The units were formed due to the emplacement of material excavated by impact processes. Inferring from the crater density and the spectral appearance (same as the surrounding material), unit c seems to be the oldest unit of the three. Because units $c b$ and cd likely consist of impact ejecta excavated from deeper layers, the different spectral behavior is possibly due to different subsurface layer material.

\subsection{Crater ray material bright (unit crb)}

Description: Crater rays on Ceres occur as bright or dark deposits around craters but only the bright ones are common in the Haulani quadrangle. These deposits occur as bright streaks or radial halos around the Haulani impact crater and cover the adjacent terrain with a more or less thin layer. This unit exhibits a high albedo compared to the surrounding terrain in the FC clear filter images, as well as a bluish signature in the enhanced color mosaic and color ratio composite A. Type area: lat. $5.8^{\circ} \mathrm{S}$, long. $10.7^{\circ} \mathrm{E}$.

Interpretation: This unit likely consists of impact ejecta excavated from deeper layers, similar to those on the Moon. Inferring from the superposition of the rays, the fresh bluish signature in the enhanced color mosaic and analogues to the lunar rays, which are supposed to be relatively young ( $\leq 1 \mathrm{Ga}$ ) (e.g., Jaumann et al., 2012;
Melosh, 1989), this unit seems to be one of the youngest features on Ceres.

\section{Haulani impact crater}

The most prominent feature in quadrangle Ac-6 is the Haulani impact crater with its bright interior and extensive ejecta with farranging crater rays of about $160 \mathrm{~km}$ to $490 \mathrm{~km}$ (Fig. 11). The high albedo of Haulani was first recognized in Hubble Space Telescope (HST) images by Li et al. (2006) and then observed in greater detail in the Dawn FC Approach and Survey images (Li et al., 2016). Furthermore, Haulani's bright albedo correlates well with the white to blue signature in the enhanced FC colors (Fig. 11).

We mapped the morphology of Haulani at a scale of 1: 250,000 and correlated it with the FC color and VIR data. Several different units could be defined and show the complexity of the crater (Fig. 13). In particular, different lobate units are found within and outside the crater, as well as a diversity of smooth units (Fig. 13). Haulani shows an overall smooth bright crater floor with flow features and some cracks in the floor's northwestern part, parallel to the impact crater rim (Fig. 13). This crater exhibits a hummocky elongated mountainous ridge in the central part of the crater with flows running downslope the ridge crest (Fig. 3). The ridge, with a maximum length and width, $21.8 \mathrm{~km}$ and $3.7 \mathrm{~km}$, respectively, and a maximum height of $300 \mathrm{~m}$, trends east-west direction. The depth to diameter ratio $(d / D)$ of Haulani with $d_{a}=0.09$ (Fig. 12) compares well with other younger craters on Ceres such as Dada $\left(d_{\mathrm{a}}=0.08\right)$, Oxo $\left(d_{\mathrm{a}}=0.12\right)$ (Hughson et al., 2016) or other young craters (Buczkowski et al., 2016). Older craters, however, tend to have a lower depth to diameter ratios due to erosion and infill (compare with Kerwan $\left(d_{\mathrm{a}}=5\right)$ (Bland et al., 2016)). The diameter of Haulani was defined by the average of E-W and N-S measurements and the depth by the average of the four rim height estimates to the deepest point on the crater floor.

The crater walls show different textures. Rock slides and a collapsed part of the crater rim (see Fig. 3b) occur along the western crater wall, followed by a steep fresh crater wall with little lobate landslide material, mostly covered by crater floor material. 

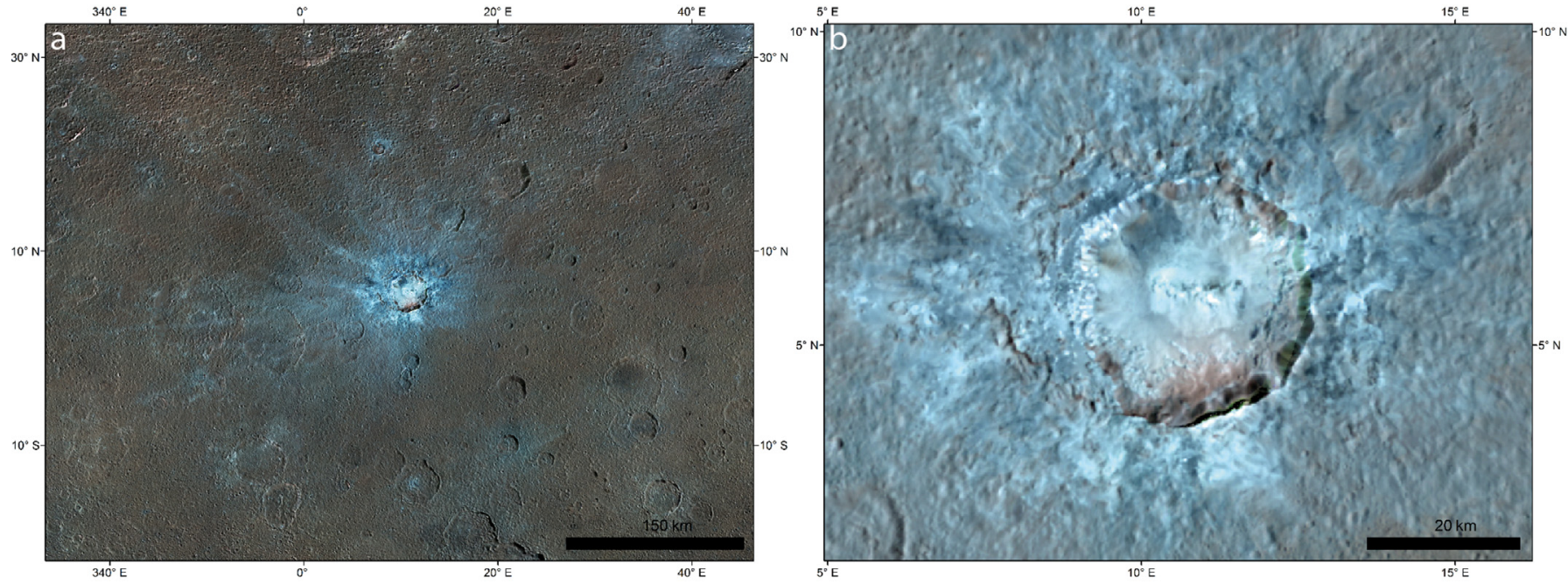

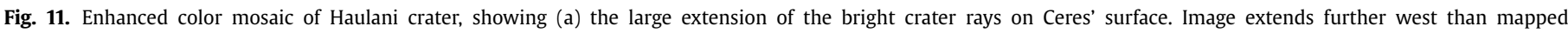

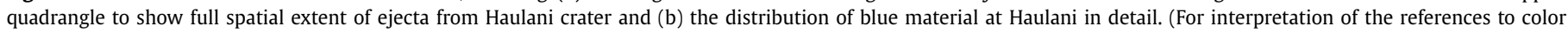
in this figure legend, the reader is referred to the web version of this article.)
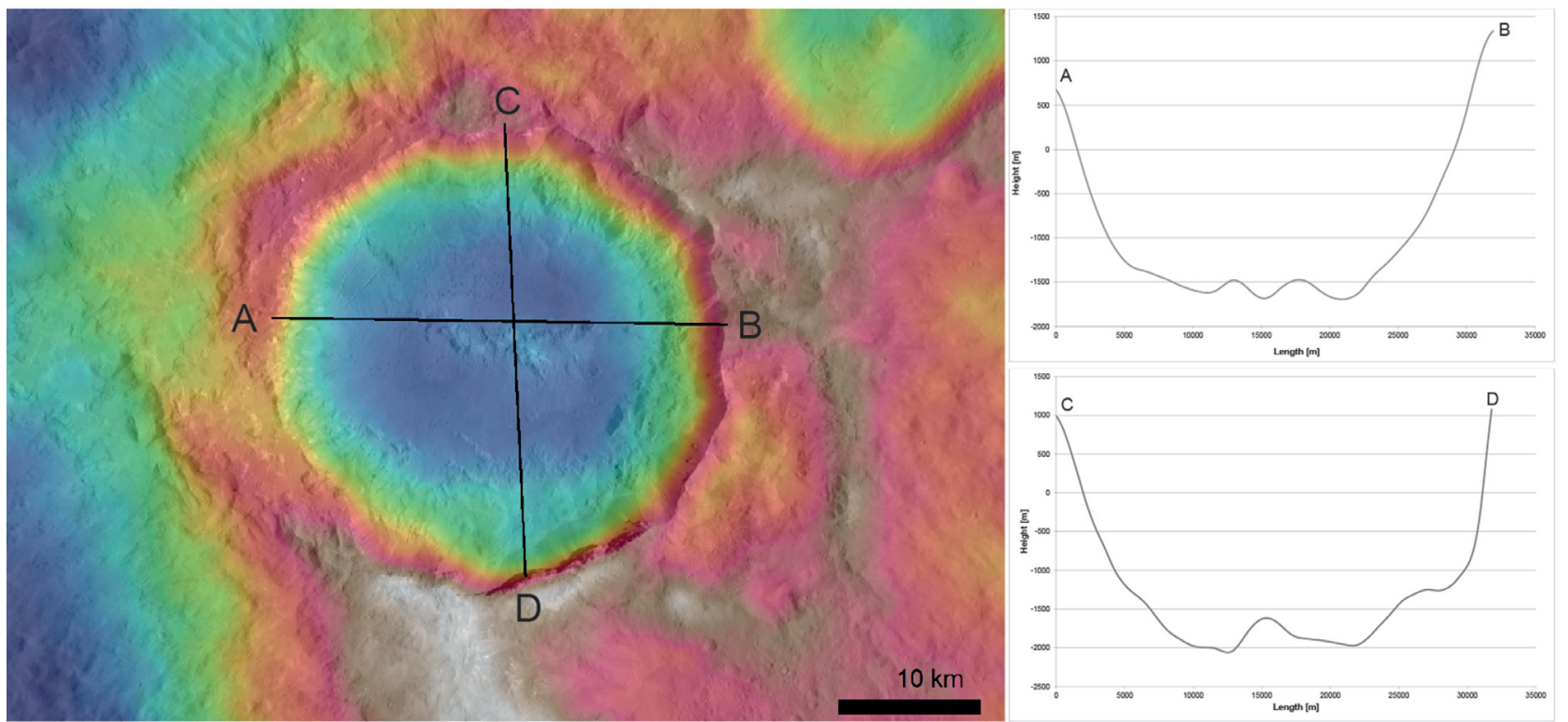

Fig. 12. Profiles of Haulani crater in WE and NS direction showing the depth to diameter ratio $(d / D)$ with $d_{\mathrm{a}}=0.09$.

The northern and eastern parts show a steep smooth wall at the top followed by slumping blocks, forming smaller and larger steps along with smoother lobate landslide material (Fig. 13).

The southern part exhibits a steep crater wall merging into a hummocky terrain covered by flows. The average slope angle of the inner crater wall, measured from the rim to the crater center, is $25-34^{\circ}$, except in the south-southeast part, where the slope is much steeper and with slope angles ranging from $40^{\circ}$ to $60^{\circ}$.

Furthermore, pitted materials occurs in the mid-northern part of the crater floor (Fig. 13) which extends to the west, in the mid-southwestern part, and in the mid-southeastern part. The pits lack raised rims and occur predominately in clusters. The largest of these clusters, with a maximum length and width of $\sim 10 \mathrm{~km}$ and $3.8 \mathrm{~km}$, respectively, is located to the north. Smaller clusters are arranged concentric about the ridge and decrease in size anticlockwise. Mass wasting deposits in these areas may comprise covered pits. The pit diameters range from $\sim 34 \mathrm{~m}$ (near the limit of LAMO resolution) to $\sim 230 \mathrm{~m}$ (Krohn et al., 2016b). Pitted ter- rain is also observed in Haulani's ejecta to the southeast of and near to the crater basin and to the west of the crater. The pits are predominantly larger than the ones observed in the crater, reaching a maximum diameter of $\sim 540 \mathrm{~m}$ (Krohn et al., 2016b). All pits are embedded in the surrounding materials, suggesting a combined formation. The pits are similar to craters on Mars (Boyce et al., 2012; Tornabene et al., 2012) and Vesta (Denevi et al., 2012). Tornabene et al. (2012) concluded that the pits on Mars are related to the formation of the particular crater. They presume that the crater-related pitted materials represent a mixture of impact melt, volatile-rich materials, and lithic fragments. Therefore, Boyce et al. (2012) and Tornabene et al. (2012) suggest that the pits were formed by the rapid degassing of volatiles. Denevi et al. (2012) argue, that pitted terrain on Vesta may have also formed due to the degassing of volatile-bearing material heated by the impact. The source of the volatiles is supposed to be exogenic material, such as water-rich carbonaceous chondrites (Combe et al., 2015; Denevi et al., 2012). 

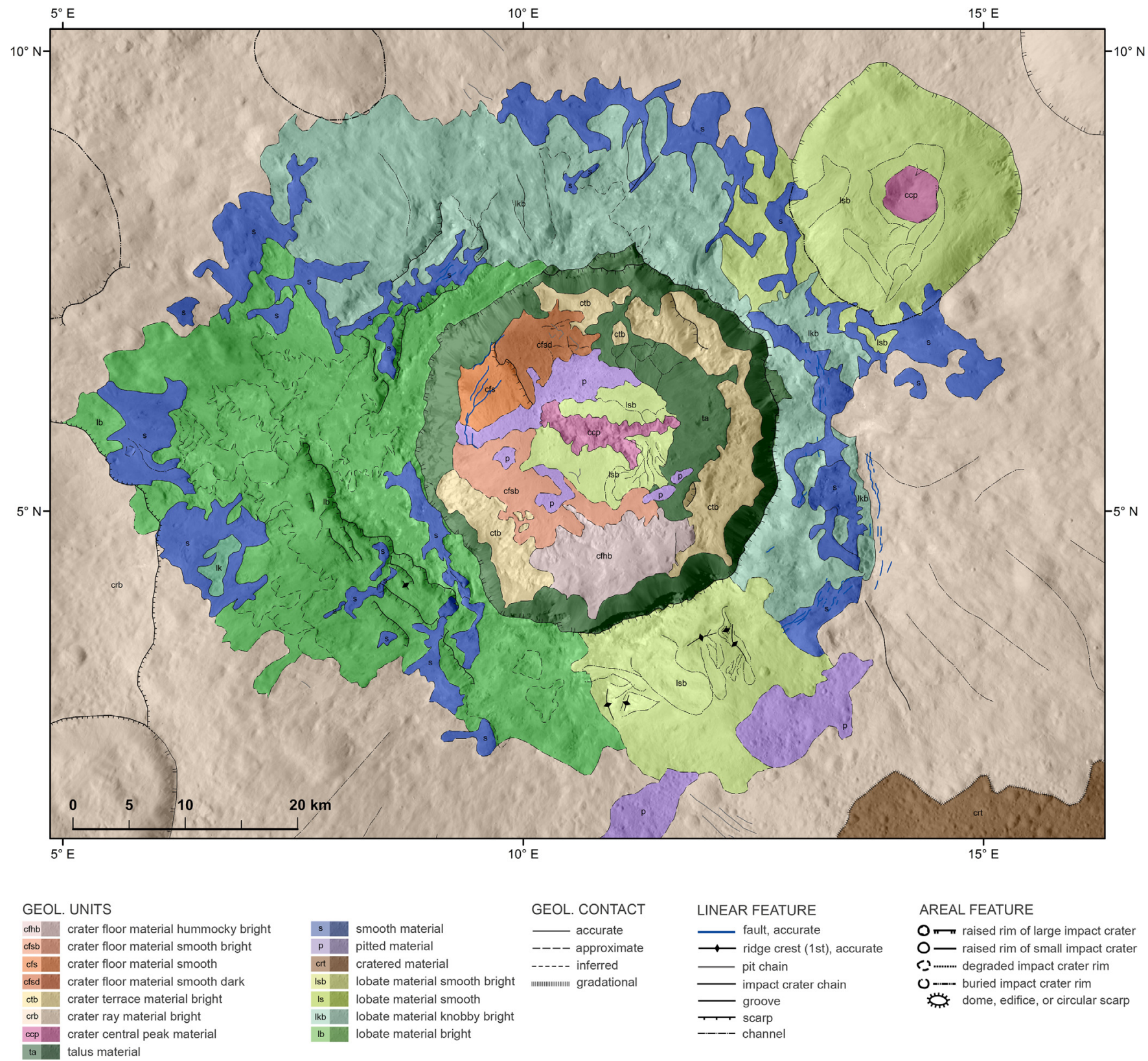

AREAL FEATURE

$O=$ raised rim of large impact crater — raised rim of small impact crater S.......... degraded impact crater rim O-...- buried impact crater rim dome, edifice, or circular scarp

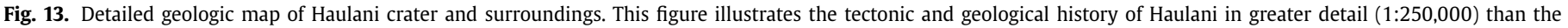
geologic map of the quadrangle shown in Fig. 9.

Ceres, however, shows evidence of a volatile-rich crust (Bland et al., 2016; Buczkowski et al., 2016; De Sanctis et al., 2016; Krohn et al., 2016b; Neumann et al., 2016). Therefore, the pits are likely due to rapid post-impact outgassing of hydrated salts or groundice (Sizemore et al., 2016).

The flanks of the Haulani impact structure exhibit three different types of lobate materials. Forming lobate flows with welldefined margins, smooth fine-grained material distributes on all lobate facies. The flows appear to have been diverted around solid blocks during their emplacement, as well as to have partly incised the crater flanks (Fig. 13) (Krohn et al., 2016a,2016b). These smooth flows are interpreted to be a mixture of impact melt and cryovolcanic flows (Krohn et al., 2016b).

Bright lobate knobby material extends around the northern and eastern parts of the crater rim, while bright smooth lobate material only occurs as smaller branches (streak-like) in the south-southeast and north-northeast parts (Fig. 13). Bright lobate material, which is particularly prominent with smooth surface and multiple flow fronts, extends to the west of the Haulani crater. This material appears to have been disrupted by multiple shear zones, interpreted largely based on the large number of scarps.

The Haulani impact crater formed on a north-south topographical transition with a higher elevation in the east and a lower elevation in the west. Materials extend into the lower plain from the collapsed western part of the crater rim (Fig. 14). The fracturing of the inner crater rim resulted in the formation of a stepwise sliding of material, which resulted in a slightly terracing. The terraces consist of several plates showing a sharp border to the following weakly pronounced talus material (see Fig. 3). The stepwise sliding of material also resulted in the formation of multiple southwestnorthwest-trending scarps that nearly parallel the former crater rim (see Fig. 3). Between the scarps, flow features are observed running down the western flank of the impact structure in multiple stages, resulting in a relatively flat slope. 

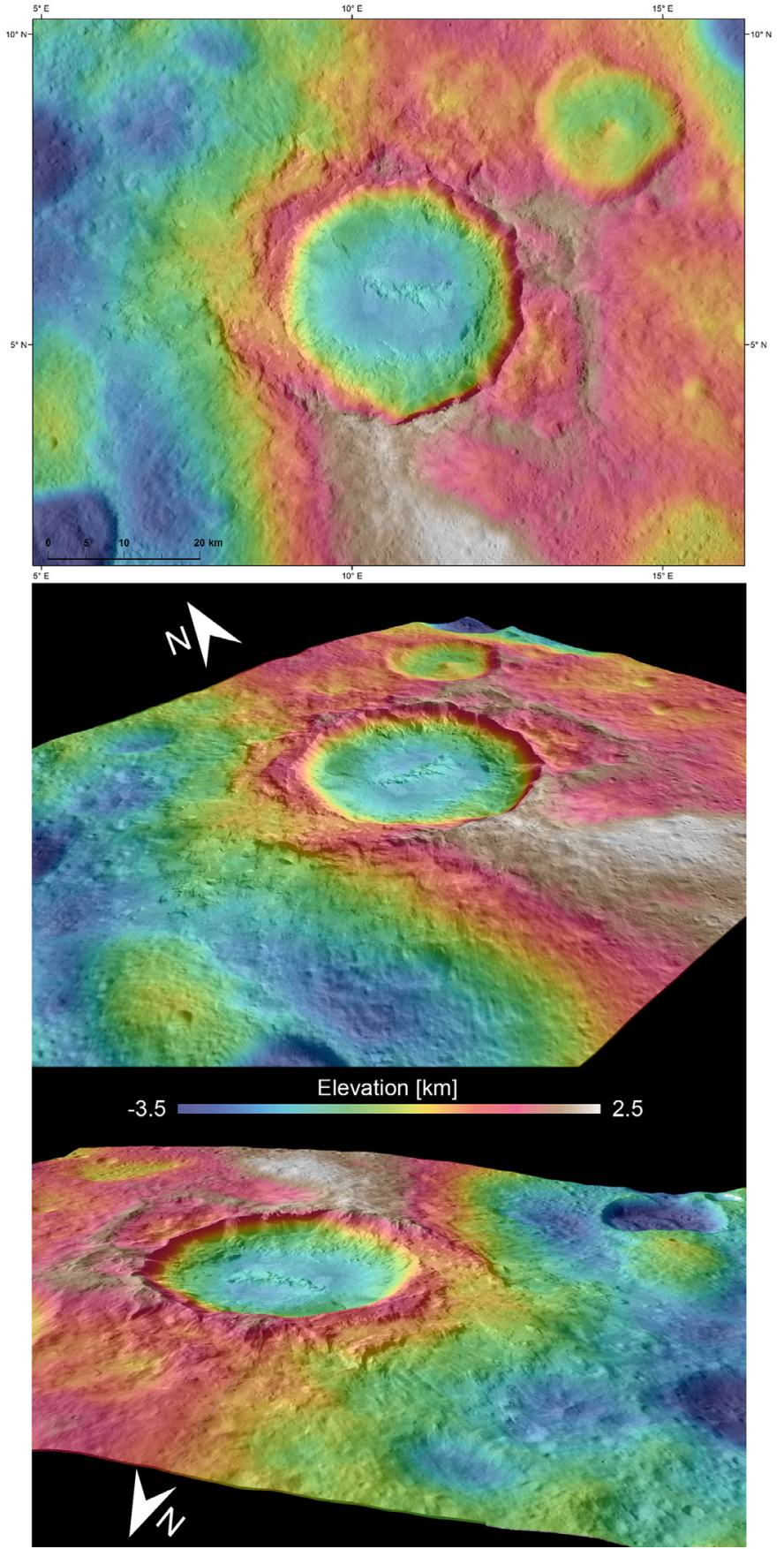

Fig. 14. 3D perspective images of Haulani crater, using a LAMO-based DTM (date: 10/08/2016) (Preusker et al., 2016). The failure of material is expressed in the depressions on the eastern and southeastern parts of the outer Haulani crater rim, as well as the collapsed western part of the crater rim, which resulted in multiple scarps bounding the flows of the western flank of the impact crater structure.

Along the southeastern outer crater rim, steep scarps occur with slope angels of up to $26^{\circ}$, ending in depressions (see Fig. 3). Moreover, sets of cracks are found to be concentric about the eastern to southeastern parts of the crater rim. This indicates the failure of the subsurface materials of the crater, and the failure to be relatively close to the impact structure. Furthermore, within the Haulani crater the crater floor material smooth dark (unit cfsd) is separated from the crater floor material smooth (unit cfs) by a scarp. The subsidence of parts of the crater floor also suggests a weaker subsurface material.
Age determinations of Haulani crater reveals a very young age for both chronology systems (Hiesinger et al., 2016). For the derivation of absolute model ages we applied the asteroid derived (ADM), as well as the lunar derived chronology model (LDM) with parameters given in Hiesinger et al. (2016) (Fig. 15). Absolute model ages are additionally presented as a probability function based on a Poisson timing analysis (Michael et al., 2016). This new approach allows for binning- and plotting technique (cumulative vs. differential) independent derivation of absolute model ages (Fig. 15). Crater counts on the proximal ejecta suggest an absolute model age of $1.67 \pm 0.28 \mathrm{Ma}$ (ADM) and $1.96 \pm 0.17 \mathrm{Ma}$ (LDM) (Figs. 15 and 16). For the smooth deposits, crater counts suggest an asteroidderived absolute model (ADM) age of $2.59+0.59 /-0.51$ Ma and a lunar-derived chronology model (LDM) age of $2.57+0.59 /-0.5 \mathrm{Ma}$ (Figs. 15 and 16). Such minor age discrepancies are possibly due to subsequent post-impact, mass-wasting processes on slopes with relatively high slope angles in parts of the ejecta. Furthermore, the observed terrain could be reasonably explained by varying material properties. The smooth deposits are either more solid or could be material that cooled down faster than the less competent (loose) ejecta material.

\section{Discussion}

Previous models suggested that Ceres is layered with a rocky core and an outer shell enriched in hydrated salts, organics, and water ice (Castillo-Rogez, 2011; Castillo-Rogez and McCord, 2010). The models include the formation of clay-like materials (e.g., Rivkin et al., 2011), which is probably covered by a regolith layer having only small-scale compositional variations (Castillo-Rogez and McCord, 2010; McCord and Sotin, 2005).

Recent Dawn observations indeed reveal a detection of ammoniated phyllosilicates (De Sanctis et al., 2015), and also a weakly differentiated body with a shell dominated by an ice-rock mixture (Fu et al., 2015). Thermal models of Ceres suggest that the dwarf planet is at least partially differentiated and could have undergone tectonic and cryovolcanic processes (Castillo-Rogez and McCord, 2010; McCord et al., 2011; McCord and Sotin, 2005). Latest modeling results by Neumann et al. (2016) show that hydrated salts could be warm enough to be mobile at a depth of $1.5-5 \mathrm{~km}$ below Ceres' surface. This process explains the buoyancy of ice and saltenriched crustal reservoirs. Thus, impacts into such reservoir layers triggered the mobility of material and could have formed cryovolcanic features like the multiple flows on the western flank of the Haulani impact structure (Krohn et al., 2016b).

Bright terrains on Ceres may display distinct thermal properties. Compared to the surroundings they show a reduced thermal emission in VIR infrared wavelengths (Tosi et al., 2016a). Haulani is the most prominent thermal feature on Ceres and reveals a significant thermal contrast. Tosi et al. (2016a) found that the temperatures in the central part of the crater structure are significantly lower than the temperature for the rest of the crater structure and the surroundings. Furthermore, the studies of Tosi et al. (2016b) suggest substantial variability of hydrous minerals and ammoniated phyllosilicates within the Haulani crater and its bright ejecta. Therefore, it is likely that ice-rich material from the subsurface was excavated and deposited as lobate material on the surface in and around Haulani. The scarps and fracture zones within and around Haulani indicate the failure of material after the impact. They were likely formed by the subsidence of material due to the instability of the subsurface. Also the depressions outside the eastern and southern parts of the crater rim indicate the failure of subsurface material. As described in Krohn et al. (2016b), the Haulani impact may have hit an unstable ice-rich subsurface layer. A discharge of this layer by the impact may have caused subsidence of the surface material and, therefore, the formation of depressions, cracks and the failure 

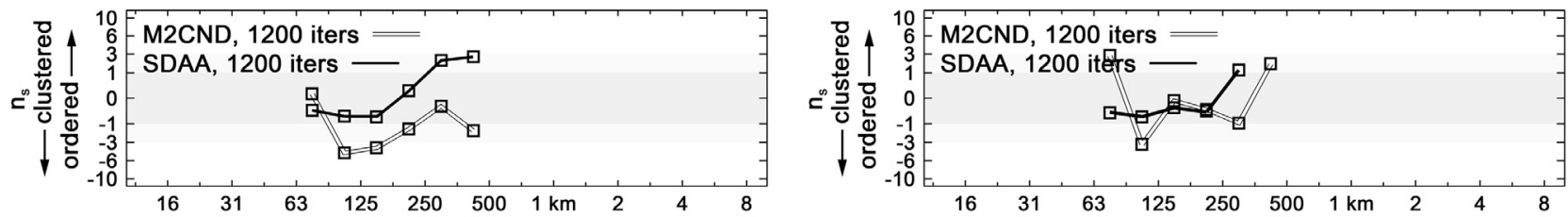

Crater diameter $(\mathrm{px})$
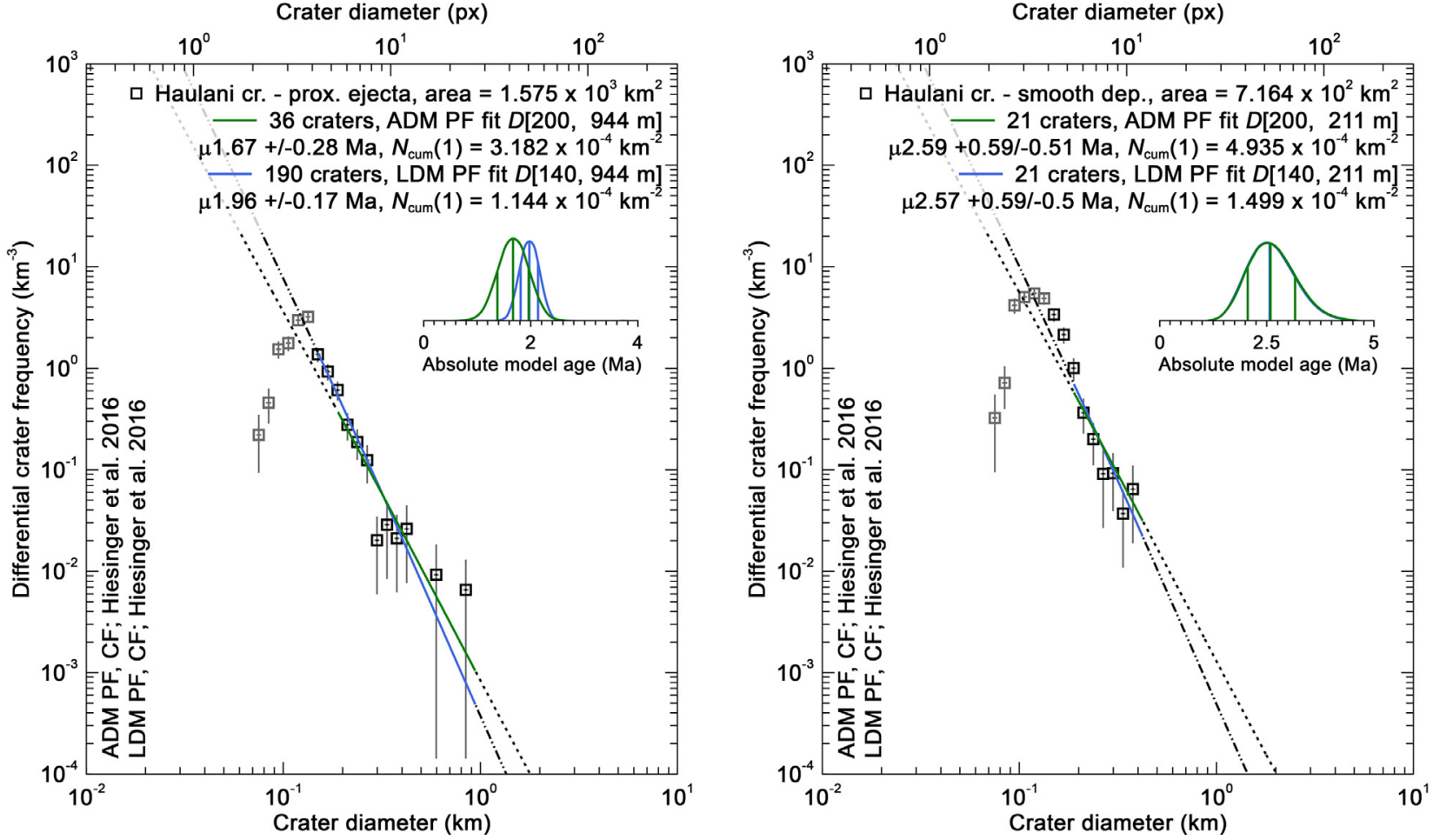

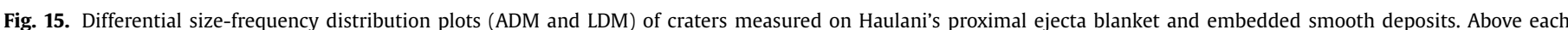

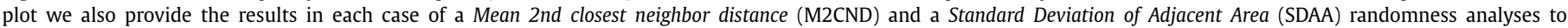
elucidate what diameters are in a more clustered or ordered spatial distribution.
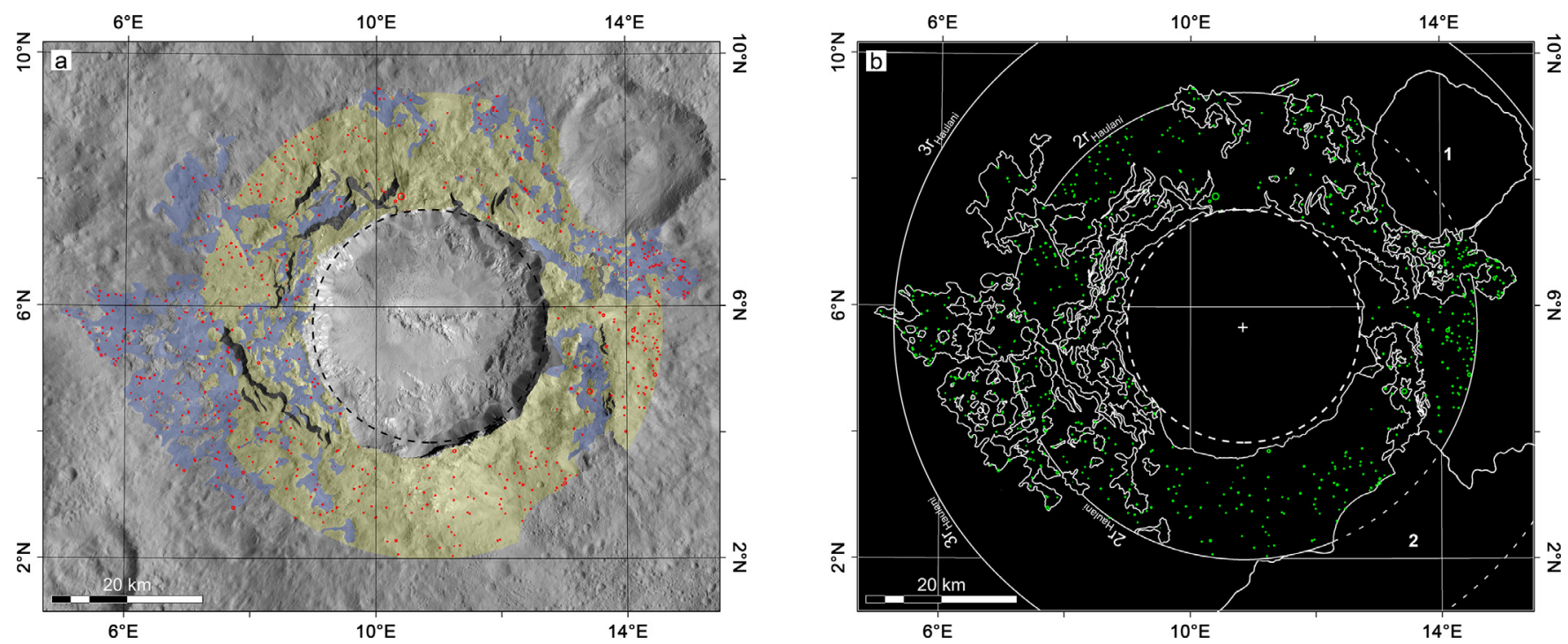

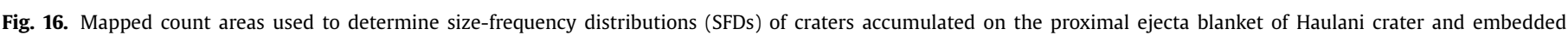

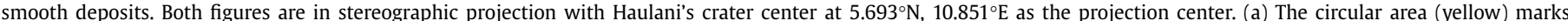

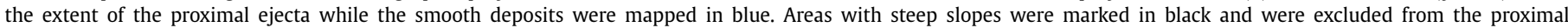

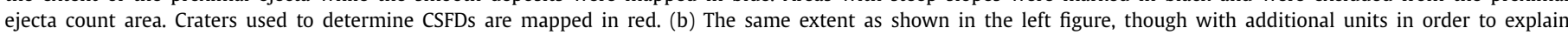

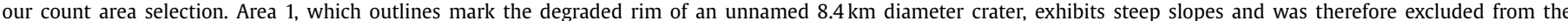

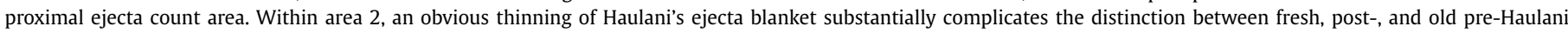

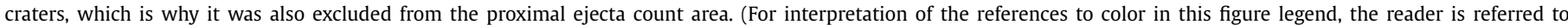
the web version of this article.) 
of the western part of the crater rim of Haulani. An inhomogeneous distribution of the ice-rich subsurface layer may result in a reasonably intact impact crater with failure structures.

\section{Conclusion}

The geologic map of Ac-6 quadrangle contains one of the youngest features on Ceres, the $34 \mathrm{~km}$ diameter Haulani crater. The complexity of this crater reveals depressions outside the crater rim, which we interpreted as failure zones. Failure zones adjacent to crater rims indicate a material change in the subsurface. Because of the mapping, we suggest that Ceres is built of layers with different material properties. We propose that Ceres has a solid crust and a spatially-varying unstable ice-rich subsurface. The uniqueness of Haulani's morphology in the Ac-6 quadrangle indicates a heterogeneous distribution of ice-rich layers on Ceres. Evidence has also been presented for ice or water-rich layers at Oxo crater, located at $42.21^{\circ} \mathrm{N}, 359.6^{\circ} \mathrm{E}$ (Combe et al., 2016). Other large unusual craters, like Occator (Krohn et al., 2016b; Scully et al., 2017), do not show any ice signature, but minerals that are the products of aqueous alteration (De Sanctis et al., 2016). Thus, heterogeneous distribution of an ice-rich subsurface layer is likely. Our geologic mappingbased observations, therefore, provide important constraints for future interior model development.

\section{Acknowledgments}

We thank the reviewers James Dohm and Pete Mouginis-Mark for their constructive comments that substantially helped improving the manuscript. We also thank the Dawn team for the development, cruise, orbital insertion, and operations of the Dawn spacecraft at Ceres. Portions of this work were performed at the DLR Institute of Planetary Research, at the Jet Propulsion Laboratory (JPL) under contract with NASA, as well as the German Aerospace Center 1(DLR). Dawn data are archived with the NASA Planetary Data System (http://sbn.pds.nasa.gov/). K. Krohn is supported by the Helmholtz Association (HGF) grant no. PD-207 through the research Helmholtz Postdoc Program.

\section{Supplementary materials}

Supplementary material associated with this article can be found, in the online version, at doi:10.1016/j.icarus.2017.09.014.

\section{References}

Bland, M.T., et al., 2016. Composition and structure of the shallow subsurface of Ceres revealed by crater morphology. Nat. Geosci. 9, 538-542.

Boyce, J.M., Wilson, L., Mouginis-Mark, P.J., Hamilton, C.W., Tornabene, L.L., 2012. Origin of small pits in martian impact craters. Icarus 221, 262-275.

Buczkowski, D.L., et al., 2016. The geomorphology of Ceres. Science 353, 6303.

Castillo-Rogez, J.C., 2011. Ceres - neither a porous nor salty ball. Icarus 215, 599-602.

Castillo-Rogez, J.C., McCord, T.B., 2010. Ceres' evolution and present state constrained by shape data. Icarus 205, 443-459.

Combe, J.-P., et al., 2015. Reflectance properties and hydrated material distribution on Vesta: global investigation of variations and their relationship using improved calibration of Dawn VIR mapping spectrometer. Icarus 259, 21-38.

Combe, J.-P., et al., 2016. Detection of $\mathrm{H}_{2} \mathrm{O}$-rich materials on Ceres by the Dawn Mission. In: Lunar and Planetary Science Conference, Vol. 47, p. 1820.

De Sanctis, M.C., et al., 2015. Ammoniated phyllosilicates with a likely outer Solar System origin on (1) Ceres. Nature 528, 241-244.

De Sanctis, M.C., et al., 2011. The VIR spectrometer. Space Sci. Rev. 163, 329-369.

De Sanctis, M.C., et al., 2016. Bright carbonate deposits as evidence of aqueous alteration on (1) Ceres. Nature 536, 54-57.

Denevi, B.W., et al., 2012. Pitted terrain on Vesta and implications for the presence of volatiles. Science 338, 246-249.

FGDC, 2006. FGDC digital cartographic standard for geologic map symbolization. Prepared for the Federal Geographic Data Committee by the U.S. Geological Survey FGDC-STD-013-2006, 290.

Fu, R.R., Ermakov, A., Zuber, M.T., Bradford, H.H., 2015. The global scale relaxation state of Ceres AGU Fall Meeting, pp. P23D-02.
Hansen, V.L., 2000. Geologic mapping of tectonic planets. Earth Planet. Sci. Lett. 176, 527-542.

Hiesinger, $\mathrm{H}$., et al., 2016. Cratering on Ceres: implications for its crust and evolution. Science 353, 6303.

Hughson, K.H.G., et al., 2016. The Ac-H-5 (Fejokoo) quadrangle of Ceres: geologic map and geomorphological evidence for ground ice mediated surface processes. Icarus.

Jaumann, R., et al., 2012. Geology, geochemistry, and geophysics of the Moon: status of current understanding. Planet. Space Sci. 74, 15-41.

Krohn, K., et al., 2016a. Channels and cryogenic flow features on Ceres. In: Lunar and Planetary Science Conference, Vol. 47, p. 2001.

Krohn, K., et al., 2016b. Cryogenic flow features on Ceres: implications for crater-related cryovolcanism. Geophys. Res. Lett. 43, 1-10.

Kuiper, G.P., 1954. On the origin of the lunar surface features. Proc. Natl. Acad. Sci. $40,1096-1112$.

Li, J.-Y., et al., 2006. Photometric analysis of 1 Ceres and surface mapping from HST observations. Icarus 182, 143-160.

Li, J.-Y., et al., 2016. Surface albedo and spectral variability of Ceres. Astrophys. J. Lett. 817, 1-7.

McCord, T.B., Castillo-Rogez, J., Rivkin, A., 2011. Ceres: its origin, evolution and structure and Dawn's potential contribution. Space Sci. Rev. 163, 63-76.

McCord, T.B., Sotin, C., 2005. Ceres: evolution and current state. J. Geophys. Res. (Planets) 110, 5009.

Melosh, H.J., 1989. Impact cratering: a geologic process. Oxford University Press, p. 253.

Mest, S.C., et al., 2017. The global geologic map of Ceres based on Dawn HAMO observations. Icarus.

Michael, G.G., Kneissl, T., Neesemann, A., 2016. Planetary surface dating from crater size-frequency distribution measurements: Poisson timing analysis. Icarus 277, $279-285$.

Nass, A., et al., 2015. GIS-based template for geological mapping - Ceres use case. Meeting ISPRS Working Group IV/8 Planetary Mapping and Spatial Databases. Berlin, Germany.

Nass, A., van Gasselt, S., Jaumann, R., Asche, H., 2011. Implementation of cartographic symbols for planetary mapping in geographic information systems. Planet. Space Sci 59, 1255-1264.

Neumann, W.O., Breuer, D., Spohn, T., 2016. Differentiation of Ceres and her present-day thermal state. In: Lunar and Planetary Science Conference, Vol. 47, p. 2307.

Otto, K.A., et al., 2016. Origin and distribution of polygonal craters on (1) Ceres. In: Lunar and Planetary Science Conference, Vol. 47, p. 1493.

Pasckert, J.H., et al., 2017. Geologic mapping of the Ac-2 Coniraya quadrangle of Ceres from NASA's Dawn Mission: implications for a heterogeneously composed crust. Icarus.

Pieters, C.M., et al., 2016. Surface processes and space weathering on Ceres. In: Lunar and Planetary Science Conference, Vol. 47, p. 1383.

Platz, et al., 2017. Geological mapping of the Ac-10 Rongo Quadrangle of Ceres. Icarus, this issue.

Preusker, F., et al., 2016. Dawn at Ceres-shape model and rotational state. In: Lunar and Planetary Science Conference, Vol. 47, p. 1954.

Rivkin, A.S., et al., 2011. The surface composition of Ceres. Space Sci. Rev. 163, 95-116.

Roatsch, T., et al., 2016a. Ceres survey atlas derived from Dawn framing camera images. Planet. Space Sci. 121, 115-120.

Roatsch, T., et al., 2016b. High-resolution Ceres high altitude mapping orbit atlas derived from Dawn framing camera images. Planet. Space Sci. 140, 74-79.

Schulzeck, F., et al., 2016. Geologic Mapping of the Ac-H-11 Sintana quadrangle of Ceres from NASA's Dawn Mission. In: Lunar and Planetary Science Conference, Vol. 47, p. 1955.

Scully, et al., 2017. Ezinu quadrangle on Ceres: a heavily cratered region with evidence for localized subsurface water ice and the context of Occator crater. Icarus, this issue.

Sierks, H., et al., 2011. The Dawn framing camera. Space Sci. Rev. 163, 263-327.

Sizemore, H.G., et al., 2016. Preliminary constraints on the volumetric concentration of shallow ground ice on Ceres from geomorphology. In: Lunar and Planetary Science Conference, Vol. 47, p. 1628.

Skinner Jr., J.A., Tanaka, K.L., Stansbery, E., 2003. How should planetary map units be defined? In: Mackwell, S. (Ed.). In: Lunar and Planetary Institute Science Conference Abstracts, Vol. 34, p. 2100.

Tornabene, L.L., et al., 2012. Widespread crater-related pitted materials on Mars: further evidence for the role of target volatiles during the impact process. Icarus $220,348-368$.

Tosi, F., et al., 2016a. Thermal behavior of bright spots on Ceres. In: Lunar and Planetary Science Conference, Vol. 47, p. 1883.

Tosi, F., et al., 2016b. Mineralogy of Crater Haulani on the Dwarf Planet Ceres. Pasadena, CA, USA DPS 48/EPSC 11

Wilhelms, D.E., 1990. Geologic mapping. In: Greeley, R. (Ed.), Planetary Mapping, p. 208.

Williams, D.A., Buczkowski, D.L., Mest, S.C., Scully, J.E.C., Platz, T., Kneissl, T., 2017a. Introduction: the geologic mapping of Ceres. Icarus.

Williams, D.A., et al., 2017b. The geology of the Kerwan quadrangle of dwarf planet Ceres: investigating Ceres' oldest impact basin. Icarus.

Williams, D.A., Yingst, R.A., Garry, W.B., 2014. Introduction: the geologic mapping of Vesta. Icarus 244, 1-12. 